\title{
Navigate flying molecular elephants safely to the ground: mass-selec- tive soft landing up to the Mega-Dalton range by Electrospray Con- trolled Ion-Beam Deposition
}

\author{
Andreas Walz, Karolina Stoiber, Annette Huettig, Hartmut Schlichting* and Johannes V. Barth*. \\ Physics Department E20, Technical University of Munich, 85748 Garching, Germany.
}

\begin{abstract}
The prototype of a highly versatile and efficient preparative mass spectrometry system used for the deposition of molecules in ultra-high vacuum (UHV) is presented along with encouraging performance data obtained on model species which are thermolabile or not sublimable. The test panel comprises two organic compounds, a protein, and DNA covering a 4-log mass range up to 1.7 MDa as part of a broad spectrum of analyte species. Three designs of innovative ion guides, a novel digital mass-selective quadrupole (dQMS) and a standard electrospray ionization (ESI) source are combined to an integrated device, abbreviated Electrospray Controlled Ion Beam Deposition (ES-CIBD). Full control is achieved by i) the square-wave-driven radiofrequency (RF) ion guides with steadily tunable frequencies, including a dQMS allowing for investigation, purification and deposition of a virtually unlimited $\mathrm{m} / \mathrm{z}$ range, ii) the adjustable landing energy of ions down to $\sim 2 \mathrm{eV} / \mathrm{z}$ enabling integrity-preserving soft-landing, iii) the deposition in UHV with high ion beam intensity (up to $3 \mathrm{nA}$ ) limiting contaminations and deposition time, and iv) direct coverage control via the deposited charge. The maximum resolution of $R=650$ and overall efficiency up to $T_{\text {total }}=4.4 \%$ calculated from solution to UHV deposition are remarkable as well, while the latter is mainly limited by the not yet optimized ionization performance. In the setup presented, a scanning tunneling microscope (STM) is attached for in situ UHV investigation of the deponents demonstrating a selective, structure-preserving process and atomically clean layers.
\end{abstract}

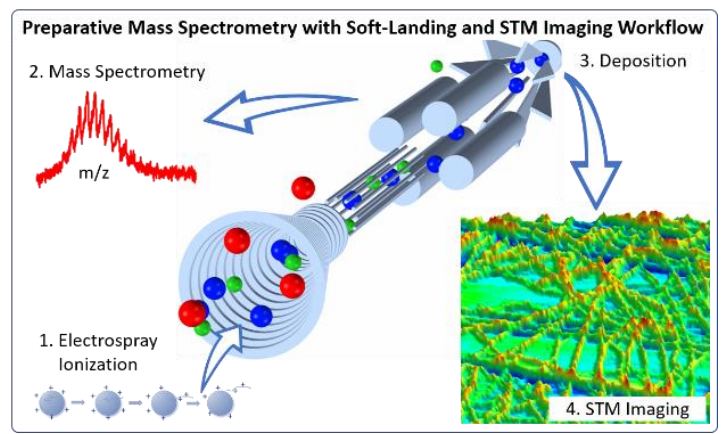


Ion beams with hyper-thermal kinetic energies belong to the most versatile tools in chemistry, life science, nanotechnology, and surface science. In the analytical field, they are the basis of commercial mass spectrometers. The ions typically originate from an Electrospray Ionization (ESI) source, a cluster source, Matrix-Assisted Laser Desorption Ionization (MALDI) ${ }^{1,2}$, or molecules gathered from a surface under ambient conditions by Desorption ESI (DESI) ${ }^{3,4}$ or Direct Analysis in Real Time $(\mathrm{DART})^{2,5}$ - even directly from the tissue of living organisms. The ions are guided through differentially pumped vacuum stages and analytical devices, finally they are detected while discarded irreversibly. Complementary to these analytical applications, high flux ion beams serve preparative purposes on a deposition target. Beam-energies below $10 \mathrm{eV} / \mathrm{z}$ are employed for soft-landing, i.e., gentle coating of sample-targets thereby functionalizing these ${ }^{6-9}$. Above $10 \mathrm{eV} / \mathrm{z}$ reactive landing of molecules or clusters prevails, whereas energies substantially above $100 \mathrm{eV} / \mathrm{z}$ lead to implantation of atoms or are used for lithographic purposes ${ }^{10-12}$.

Deponents and Integrity: Starting 1977, Cooks pioneered soft-landing and reactive-landing of mass-selected small ions using a home-built machine that runs at deposition energies as low as $10 \mathrm{eV} / \mathrm{z}$ and beam currents up to $10 \mathrm{nA}$ under Ultra-High Vacuum (UHV), generated in an electron impact source ${ }^{13-15}$. Hereafter, soft-landing has been defined as the deposition of intact species of proper integrity ${ }^{16}$. In 1999 soft-landed DNA was recovered from a membrane, and its functionality was proven by subsequent analysis via PCR ${ }^{17}$.

Cooks trailblazing experiments in 1977 opened up new pathways towards preparative approaches, though most organic molecules may not be ionized by electron impact. However, ESI sources offering soft-ionization, suffer from low beam intensities and overall efficiencies. Thus, several scientific groups stepwise improved their home-built deposition systems aiming purification and selection of organic substances and the manufacturing and commercialization of functionalized materials.

Soft and reactive landing under controlled variable kinetic energies - reviewed by Cooks ${ }^{18}$ - became the focus of Laskin's ${ }^{7,19-26}$ and other groups ${ }^{27,28}$. The technology was applied for the investigation of molecular magnets ${ }^{29}$, organometallic complexes $^{24,30-32}$ and the redox-activity on surfaces ${ }^{33}$. The possibility to generate chemical gradients on PMMA films ${ }^{34}$ was demonstrated and self-assembled monolayers (SAMs) were examined by Cooks and coworkers ${ }^{15,16,35,36}$.

Strong scientific interest in clusters ${ }^{37-43}$ such as the catalytical activity of nanoclusters prepared by ion-beams ${ }^{24,44-47}$, and in carbon-based materials such as graphene ${ }^{48,49}$, carbon nanotubes $^{50}$ and carbon nanoribbons ${ }^{51,52}$ drives activities apart from ESI-based techniques.

The tremendous success of analytical mass spectroscopy focusing on (bio)organic species (metabolites, peptides, proteins and its complexes), pushed the attention to preparative aspects of these molecules as well. Protein arrays became of strong industry interest ${ }^{53-56}$, but their fabrication is driven by economic aspects $^{57}$. Though proof of concept for preparative soft-landing of mass-selected, purified proteins or peptides ${ }^{35,53-55}$ as well as reactive landing for covalent immobilization of biomolecules $^{22,61}$ was demonstrated, the low intensity of the ion-beam blocked maturation to a commercial level. At present, the conformation of biological relevant molecules on surfaces comes into scientific focus ${ }^{60,62-66}$

Instrumental Evolution: Compared to Cooks' first experiments ${ }^{13}$, the instrument-based progress achieved to date is significant. Nearly none of the original components survived, however their functionality was adopted by other elements, seeking to raise beam intensity and quality, throughput, resolution and purity, or reducing complexity.

Cook's first machine operated with DC-driven Einzel lenses to guide ions. RF-quadrupoles, a complementary principle, was introduced around 1953 by Paul et. al. ${ }^{67-70}$, initially for use as mass separators only. These rod-based multipoles use RF-voltages of opposite polarity at neighboring electrodes to form a confining potential for ions. Nowadays both, rod arrangements and Einzel lenses ${ }^{13,40}$, are used in the low-pressure regime where the mean free path of the ions exceeds the (lateral) dimensions of the guide. Four rods, or rarely up to eight, are common for linear ion guides. Ion traps are equipped with up to 22 rods $^{71-75}$. The dimensions and shape of these rod-systems are investigated closely, mainly in their function as mass-selective ion guides ${ }^{76-95}$. The high-pressure regime however is supplied by plate-based or stacked-ring ion guides, colloquial called funnels. The group around Smith ${ }^{96-102}$ evolved this concept based on an idea of Gerlich ${ }^{83,103-106}$.

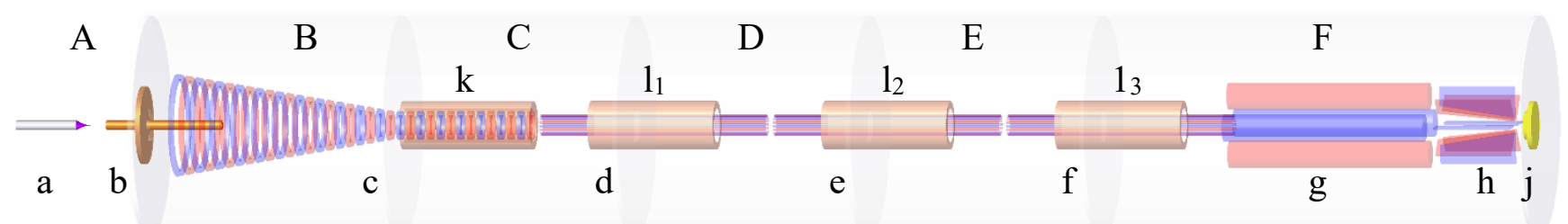

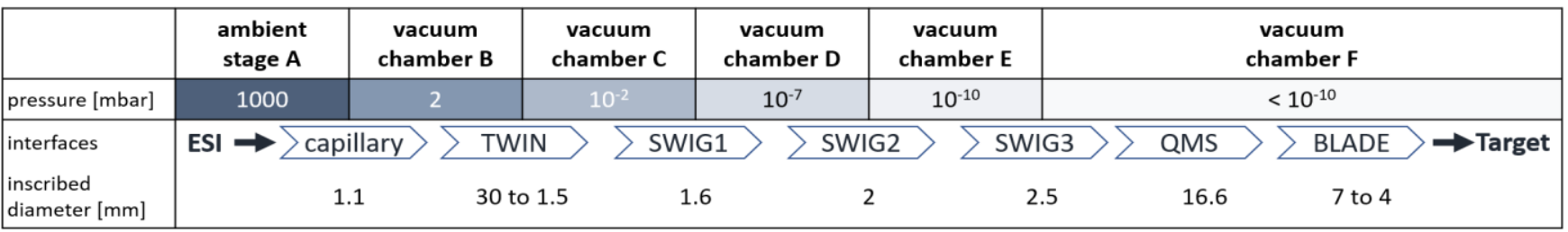

Figure 1. Overview and key parameters of the ES-CIBD system: (A) Electrospray under ambient conditions. (B)-(F) Subsequent, differentially pumped vacuum chambers. (a) Electrospray emitter at high voltage. (b) Capillary with funnel shaped inlet acting as counter electrode and vacuum interface. (c) Combined funnel and tunnel, forming the TWIN ion guide with strongly reduced gas-load. (d, e, f) Small Wire Ion Guides (SWIGs) with strongly reduced gas-load. (g) Digital Quadrupole Mass Spectrometer (dQMS) with virtually unlimited m/z range. (h) BLADE ion guide to refocus the beam. (j) Target on which ions are soft-landed. (k, l) Gas-load reduction tubes. Operation pressure and clear diameters of the respective ion guides are summarized in the table. Refer to details in the SI. 
O'Shea's group removed all Einzel lenses, ion guides and mass-selective components and simplified the design by skimmers ${ }^{107-109}$. A similar approach directly injects the liquid thus omitting an ESI source ("pulse injection" or "spray jet technique") ${ }^{110-113}$. These loan designs suffer from the lacking mass selection which results in poor cleanliness and a high impact energy of the frozen solvent. Turecek's group made a tradeoff between simplicity and beam quality by combining a funnel with an octupole ${ }^{114-116}$. The reduction of building-blocks by a rotating field was proposed ${ }^{117}$ and realized later ${ }^{118-120}$. Direct ESI-spraying into sub-ambient pressure reduces pumping effort and enhances ionization efficiency ${ }^{107,121-125}$. MEMS-(microelectro-mechanical systems) based ion guides for lossless ion manipulation ${ }^{126-128}$ enable smaller and more versatile deposition devices.

Though beam quality, operability and source universality were improved, it had only little effect on the beam intensity. Multiple needles ${ }^{129-131}$ and simultaneous deposition of molecules with different $\mathrm{m} / \mathrm{z}$ under magnetic support ${ }^{132,133}$ were proposed and tested to raise beam intensity and throughput. Improvement of the vacuum interface introducing an inlet-shaped aerodynamic transfer capillary considerably promoted both, beam intensity and ion transmission ${ }^{134-136}$

Additionally, chemical noise and sediments in the ion path were reduced by implementing a jet disrupter in the funnel de$\operatorname{sign}^{100,137,138}$. Removal of unwanted neutrals is also achieved by altered beam geometry: folding ${ }^{139}$ or bending beams orthogonally in a transvers quadrupole $\mathrm{e}^{19,23,42,140-146}$, or by curved ion guides $^{147-149}$. The latest approach is the orthogonal arrangement of the transfer-capillary relative to the ion-funnel ${ }^{42,146,150,151}$, Additionally, this allows for multiple and multiplexed spray-systems in parallel ${ }^{149,152}$.

In 1977, a Wien filter was used for mass selection ${ }^{13}$, whereas the upcoming Quadrupole Mass Spectrometer (QMS) does not require magnetic fields ${ }^{67-70}$, why it became predominant in both, analytic and preparative MS. Ion traps, implemented in Time Of Flight (TOF) MS, Fourier Transform Ion Cyclotron Resonance (FT-ICR) $\mathrm{MS}^{153}$ or Orbitraps ${ }^{154-156}$, are powerful strategies to increase resolution with the latter becoming dominant in analytical MS. However, since any trap delivers poor, discontinuous beam intensity and prohibits post-analytical usage of the ions, they are ineligible from a preparative view. Homogeneous depositions require precise selection of a target species. From current preparative designs ${ }^{13,132,147,157}$ resolutions exceeding 100 are not reported, however mass analyzers allowing for higher intensities come into focus ${ }^{117-120}$.

Taking the highly promising concept of preparative mass spectrometry up, we performed a substantial re-engineering: We introduce three innovative ion guide designs, optimized towards high transmission, high flux and low residual gas load. A novel digital QMS (dQMS) operating in an unsual squarewave signal mode provides virtually unlimited mass range of the analyte species. Both in combination with a classical operating ESI source, embodies a new, versatile tool for atomic clean nano-preparations as needed in modern surface science. The integrated system abbreviated ES-CIBD ("electrospray controlled ion beam deposition") allows for full control of mass, energy and quantity of the ions. Experiments on several test objects recruited from a broad range of chemical classes demonstrate high versatility and performance of the system. Based on these data overall potential of the device is assessed and compared to the state of the art.

\section{EXPERIMENTAL SECTION}

A short overview of the ES-CIBD system in its actual realization is shown in Figure 1: An ESI source operating at ambient pressure (A) produces ions from the liquid provided in the emitter (a). The ions are transferred through a funnel shaped ${ }^{158}$ capillary (b) into the first vacuum chamber (B). The subsequent differential pumping chambers $(\mathrm{B}-\mathrm{F})$ separate the ions from the unwanted neutrals on their way to the deposition target $(\mathrm{j})$ in UHV. They are guided along their path by an RF ion funnel combined with an ion tunnel (TWIN) (c), and three Small Wire Ion Guides (SWIG) (d, e, f). A dQMS (g) operates as mass selector. The focusing BLADE ion guide (h) leads the ions to the sample target $(\mathrm{j})$.

ESI ion source. In the setup presented a home-built conventional ESI source without sheath gas assistance (only occasionally operated in an ambient $\mathrm{CO}_{2}$ environment) is attached to the CIBD system. The emitter (a) is cut from uncoated fused silica tubes with an inner diameter of 50 or $75 \mu \mathrm{m}$. It opens into a heated capillary (b) acting as counter electrode and interface to transmit the ions from the spraying plume into the first vacuum chamber (B). The design of the capillary is adapted from Rauschenbach ${ }^{134}$. It consists of a funnel shaped inlet followed by a $6 \mathrm{~cm}$ long tube with a clear diameter of $1.1 \mathrm{~mm}$.

TWIN ion guide. The gas phase ions leaving the capillary (b) are confined and focused by a novel TWIN ion guide (c). It consists of a standard ion funnel section for focusing ${ }^{83,96}$ located in the first chamber (B), and a tubular sealed ion tunnel section extending into the subsequent chamber (C). Ring electrodes made from metal sheets with $0.2 \mathrm{~mm}$ thickness and $0.2 \mathrm{~mm}$ spacing keep the ions in path. This elongated pressure interface significantly reduces the gas load compared to a typical thin orifice ${ }^{83,138,159,160}$ by a factor of about 20 , while preserving the confining properties of the RF field. Another important feature of the TWIN is the applied variable square wave RF frequency, steadily adjustable from $\mathrm{kHz}$ to a few $\mathrm{MHz}$ and separately provided to funnel and tunnel region. The optimum in the amplitude / frequency space is chosen, to match the $\mathrm{m} / \mathrm{z}$ ratio of a guided ion of interest, for maximum transmission. This feature pertains for all other ion guides as well.

SWIG ion guide. The novel SWIG $(\mathrm{d}, \mathrm{e}, \mathrm{f})$ is a high order multipole made from tensioned super-thin wire electrodes. The advantage of this device is its small total diameter and the strongly reduced profile of the electrodes. Thereby and due to the tube surrounding the wires (1), the gas-load between the stages is reduced by a factor of 10 while the RF-field is steadily kept. The smallest SWIG adopted consists of 16 wire electrodes of $0.18 \mathrm{~mm}$ diameter aligned in parallel and uniformly distributed on a circle around a central axis with a clear diameter of $1.6 \mathrm{~mm}$, defining the very upper diameter of the ion beam. The high number of electrodes generates a short-range high order multipole field with steep effective potential walls for a nearly lossless transfer of ions and an almost field-free center region ${ }^{83}$. This field-free area allows for injection and transfer of ion beams with a size closely to the clear diameter. A further advantage of the small distance between the electrodes is the low RF-voltage needed, resulting in a strongly reduced upper limit for the transfer of kinetic energy to the guided ions.

dQMS mass selector. A common $19 \mathrm{~mm}$ quadrupole rod system from Extrel with pre- and post-filters is operated with home-built electronics. Unlike every commercial QMS known to us, it does not operate with a resonantly generated sineshaped voltage, but in a "digital" mode. The RF signal is a computer-controlled square wave with steadily variable frequency 
and amplitude. Due to the tunable frequency which is adapted to the mass of the molecules under investigation, the optimum resolution $R$ for each molecule can be chosen. There is virtually no limit for the accessible $\mathrm{m} / \mathrm{z}$-range of the transmitted molecules. To our knowledge this flexibility is currently not achieved by any other QMS. The dQMS accomplishes both tasks of the CIBD system - the analysis of the ion beam and the selection of distinct species during deposition.

BLADE ion guide. A BLADE (h) consists of 16 radially arranged metal sheet electrodes, which approximate a conical high order multipole. The electrode sheets have a thickness of $0.5 \mathrm{~mm}$ and focus the ions from $7 \mathrm{~mm}$ diameter at the inlet to 4 $\mathrm{mm}$ at the outlet, adapted to the sample diameter.

Further details of the components are provided in the SI.

\section{RESULTS AND DISCUSSION}

The described new CIBD soft landing system was tested by means of a standard ESI source and an STM, to demonstrate its flexibility. The sprayed molecules were chosen in accordance to the parameters to be tested. Surface data presented refer to ions soft-landed on a $\mathrm{Ag}(111)$ single crystal for further investigation by a variable temperature STM in UHV.

Resolving isotopologues of Rhodamine B: The frequently used test molecule Rhodamine $\mathrm{B}^{161-168}$ was sprayed in a positive mode generating an ion beam dominated by the single charged cation (Figure 2). The overview spectrum and the inset give a first idea of the tradeoff between high selectivity for clean depositions and high transmission for fast depositions. For the overview spectrum, a resolution of about $R=\frac{m / z}{\Delta m / z}=110$ (FWHM) was chosen. Some minor intensity peaks are found at slightly lower $\mathrm{m} / \mathrm{z}$, but only one very dominant charge state of the Rhodamine B cation is present at 443 Th. The inset of Figure 2 presents a series of spectra with increasing resolution up to $R=670$ revealing a second peak of the Rhodamine $\mathrm{B}$ cation, approximately one mass apart from the main peak. This is attributed to an isotope, generated by a single $\mathrm{C}^{13}$ atom in the molecule in an arbitrary position. The natural abundance of $\mathrm{C}^{13}$ of about $1 \%$ translates into a prevalence of $28 \%$ in the Rhodamine B isotopologues with 28 potential C positions ${ }^{2,169,170}$. This value is experimentally confirmed by the relative height of the $\mathrm{C}^{13}$-containing peak versus the "main" peak with $100 \% \mathrm{C}^{12}$ con-

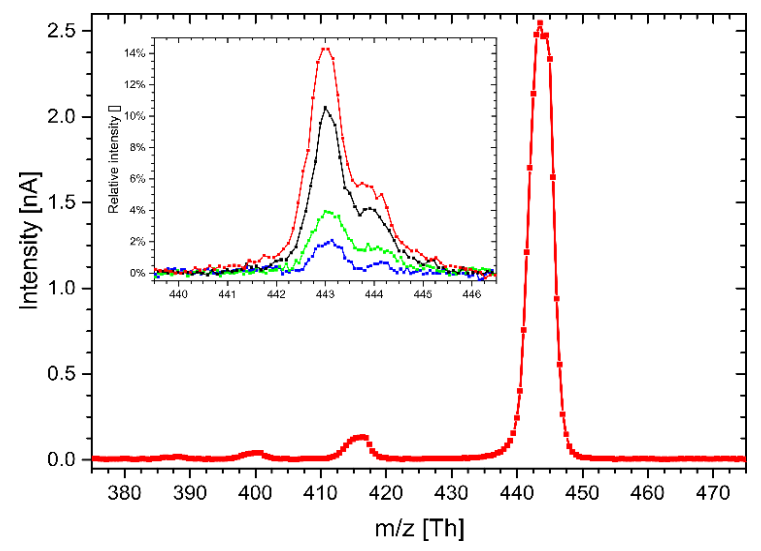

Figure 2. Main: High intensity mass spectrum of Rhodamine B with a resolution $R=110$ (FWHM) dominated by the single charged cation. Inset: Spectra from resolution assessment with $R=530$ (red) to $R=670$ (blue); $\mathrm{m} / \mathrm{z}=443 \mathrm{Da}$ for the all$\mathrm{C}^{12}$ isotopologue; $\mathrm{m} / \mathrm{z}=444 \mathrm{Da}$ for species with a single $\mathrm{C}^{13}$. Transmission scale in the inset is normalized to $100 \%$ at $R=55$. tent (Figure 2). Notably, unlike many other deposition instruments $40,52,147,171,172$ beam characterization and deposition are performed with the same $\mathrm{m} / \mathrm{z}$-selective device. Though the resolution is lower, e.g., compared to a TOF, our design works as "what you see is what you get" on the sample.

The advantage of Rhodamine B as a test molecule is its very decent spray behavior due to its high solubility and its ionic nature, as well as its high stability and availability. According to the mass spectrum the ion beam almost exclusively consists of one ion species. Thus, Rhodamine B qualifies for an ideal model system to analyze system parameters (Figure 2, Figure 6). The efficiency of an ion ejected by the ESI source, massfiltered and soft-landed on the sample surface (transmission efficiency), can be estimated to about $22 \%$ at $R=110$ (Table 1).

Charge states, conformation and adducts of Insulin: Insulin serves as test object exemplary for the group of non-elongated biomolecules. The globular $5.8 \mathrm{kDa}^{173-175}$ protein adopts several charge states in addition to the metabolic active monomeric form which dominates at physiological conditions in serum $^{176}$. Dependent on the solvent conditions, insulin builds various non-active oligomeric stages in vitro: low ionic strength, low $\mathrm{pH}$, and low concentration of the protein promote rather monomeric and dimeric states while higher $\mathrm{pH}$, higher concentration, and high ionic strength, divalent metal ions, chloride and phenolic compounds drive assembly to tetramers, hexamers or even higher structures including aggregates ${ }^{175,177-185}$.

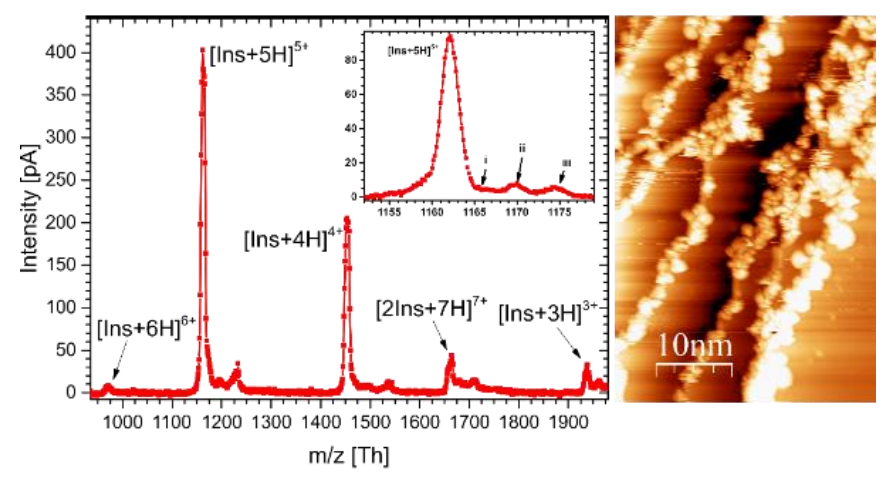

Figure 3. Left: Mass spectrum of insulin $(R=130)$ showing two prominent monomer signals ( $4+$ and $5+$ charged), two lower intensity monomer peaks ( $6+$ and $3+$ ), and an odd protonated dimer $(7+)$. Insert $(R=490)$ : Three emerging satellite peaks are attributed to adducts with (i) sodium $[\mathrm{Ins}+\mathrm{Na}+4 \mathrm{H}]^{5+}$, (ii) potassium $[\mathrm{Ins}+\mathrm{K}+4 \mathrm{H}]^{5+}$, and (iii) acetic acid [Ins $+\mathrm{AcAc}+$ $5 \mathrm{H}]^{5+}$ or $[\mathrm{Ins}+\mathrm{K}+\mathrm{Na}+3 \mathrm{H}]{ }^{5+}$. (see SI). Right: Post-deposition STM image on $\mathrm{Cu}(111)$. Insulin preferably decorates step edges including building of large clusters.

Due to the virtually salt-free spray conditions and low protein concentrations at acidic $\mathrm{pH}$, primarily monomers, potentially accompanied by low yields of dimers are expected in our experiments. According to sequence, insulin in solution can be protonated at its four basic amino acids and $\mathrm{N}$-termini of its two subunits. In ESI processes, however, protein and droplet surface area, affected by flow rate and diameter of the emitter play a dominant role for charging efficiency ${ }^{186,187}$. Conducting Rayleigh limit calculations ${ }^{188}$ of a sphere at standard conditions, a monomer should carry six and a dimer eight charges at maximum, confirmed by experimental data ${ }^{177}$, while monomers with eight charges are observed using supercharging agents ${ }^{189}$.

The ES-CIBD delivered results as expected: the overview spectrum is dominated by two main peaks representing the 4+ 
and 5+ charged monomers in addition to less abundant peaks of monomeric molecules with $3+$ and $6+$ charges according to mass calculation (Figure 3). In principle, some of these peaks may be overlaid or even replaced by the respective doublecharged dimers (e.g., $[\mathrm{Ins}+3 \mathrm{H}]^{3+}$ by $[2 \mathrm{Ins}+6 \mathrm{H}]^{6+}$ ), while those cannot be distinguished by $\mathrm{m} / \mathrm{z}$ measurements. Additional low abundant peaks may be attributed to either dimers or adducts. Hints for dimers are given by a peak compatible with the odd charged oligomeric form [2Ins $+7 \mathrm{H}]^{7+}$, consistent with the analysis of the Robinson group ${ }^{177}$. For the insulin concentration tested, the respective dimers are quite likely to coexist as those emerge at levels as low as $2 \%$ of the concentration we used. The probability of dimers strongly increases with rising concentrations ${ }^{177}$. Hexamers or even higher oligomeric states seem less likely, as the electrolyte composition favors smaller entities.

Generation of adducts with monovalent metal cations (sodium, potassium) by ESI is known to intensify with increasing emitter sizes and flow rates and adversely affects resolution ${ }^{190}$. This is also reported for insulin ${ }^{187,191}$. Additionally, water adducts are described for insulin hexamers ${ }^{192}$. Possibly those adducts might emerge with our setting too, as suggested by the details in the insert of Figure 3. In particular, three low-intensity signals appear in close proximity to the $5+$ charged variant. By calculating the calibrated mass these can be attributed to insulin 5+ monomers carrying single sodium or potassium ions ${ }^{193}$, or a single acetic acid (AcAc) molecule (Figure 3, insert, peaks (i), (ii) and (iii) respectively). The likelihood of other adducts are discussed in a mass deviations assessment (SI). Similar observations are made for the 4+ peak (data not shown).

Monomers, dimers and hexamers are considered native states of insulin. ESI, however, may produce also higher oligomers which, due to their correlation with the insulin concentration, are regarded ESI 'artefacts' ${ }^{194}$. In such event, aggregates were easily excluded by $\mathrm{m} / \mathrm{z}$-filtering during deposition. Putative aggregates, that emerge during sample preparation prior to ESI, can successfully be removed by spin-filtration ${ }^{195}$. In our case, the main peaks observed match with the theoretical masses of commonly charged monomeric and dimeric states. This and the lack of higher oligomers suggests, that the ES-CIBD system preserves the native states of the molecules.

Charge state modulation of a Porphyrin variant. The synthetic Cu-TCPP (copper incorporated 5,10,15,20-tetrakis (4carboxylphenyl)-porphyrin) with a mass of $854 \mathrm{Da}$ belongs to the group of porphyrins extensively used and investigated due to their biological relevance as reactive component in hemoglobin, chlorophyll and other biomolecules, as well as their metalorganic nature ${ }^{196,197}$. Forming nanosheets of metal organic frameworks (MOF), $\mathrm{Cu}$-TCPP is prominent in the detection of DNA $^{198-200}$. It is explored by scanning probe microscopy (SPM) in liquid ${ }^{201}$ and after classical UHV deposition techniques ${ }^{202,203}$.

We used $\mathrm{Cu}$-TCPP in an electrospray ionization setting. Ionization was achieved by negative spray mode supported by the proton acceptor ammonia. Similar to insulin, multiple charge states are present, with double and triple charged states being predominant in all settings. Higher charge states raise with higher ammonia concentration (Figure 4). Single charge states are observed as well, however at low $\mathrm{H}$-acceptor concentrations only. Exemplary, with $2 \times 10^{-4} \mathrm{M}$ and $2 \times 10^{-5} \mathrm{M}$ ammonia, intensities of $4 \%$ and $15 \%$ with respect to the main peak are seen (data not shown). Thus, modulation of charge states by varying acceptor concentration is feasible.

Our experiments on $\mathrm{Cu}$-TCPP demonstrate one advantage of ESI mass spectrometry regarding preservation and proof of the

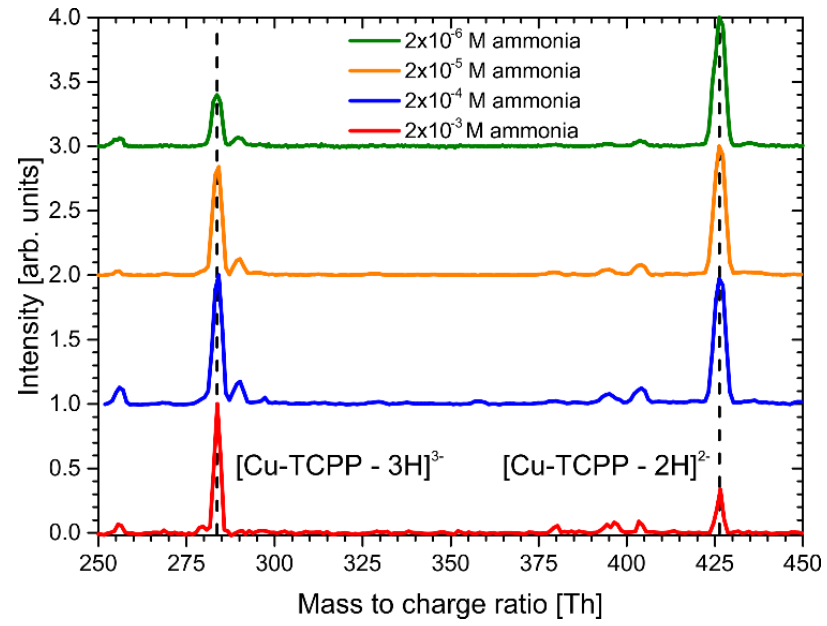

Figure 4. Mass spectrum of $\mathrm{Cu}$-TCPP $\left(8 \times 10^{-5} \mathrm{M}\right)$ in negative spray mode at varying ammonia concentrations. The values of the two main peaks are $283,7 \mathrm{Th}$ and $426 \mathrm{Th}$ respectively. Main peak intensities are normalized to 1 .

integrity of the molecules. It is an accepted fact that structural stability of evaporated organic substances becomes challenging with rising molecule size ${ }^{204-206}$. Likewise, SPM measurements become less reliable approving a specific model. Mass spectrometry may serve as a method to proof at least the weight of a deposited large organic molecule as a surrogate for its integrity. Mass can be predicted from a suitable precise mass spectrum by analyzing the peak distance of two charge states. In our case, the difference of the back-calculated masses of the double and triple charged species, agrees with the expected difference of a proton mass. This relation does not apply for any truncated molecules nor for adducts, confirming $\mathrm{Cu}$-TCPP integrity in our experiment. In contrast, upon OMBE deposition, the molecule was found impaired due to a presumed decomposition of the carboxylic groups, deduced from a carbon dioxide peak emerging in the residual gas spectrum upon annealing ${ }^{207}$. This is in accordance with the integrity-preserving nature of ESI demonstrated by other authors performing ESI deposition experiments on fragile molecules such as proteins, oligoynes, dyes, or clus$\operatorname{ter}^{28,29,32,52,58,165,208-210}$.

Impurities by fragments or residual solvent molecules in the ES-CIBD is negligible due to a stringent $\mathrm{m} / \mathrm{z}$ selection and the UHV conditions. Even the lack of two or three protons caused by the negative electrospray process - in $\mathrm{Cu}$-TCPP presumably at the carboxylic groups - will be restored after landing, since hydrogen as the dominant residual gas is still present in a "clean" UHV environment of $10^{-10} \mathrm{mbar}^{211}$.

Deposition of large string-like DNA. As a representative molecule for rather large and elongated molecules such as nucleic acids, the double-strand (ds) circular plasmid pUC19 was processed $^{212}$. The bacterial DNA, adopting a B-form helix ${ }^{213}$, consists of 2686 base pairs translating into a molecular mass of approximately 1.7 MDa. Data were obtained by spraying an aqueous solution of pUC19 with $66 \% \mathrm{ACN}$ as organic component. At these conditions, dsDNA molecules carry negative charges predominantly on the phosphate backbone accessible for electrospray ionization in negative mode.

In the mass spectrum, pUC19 appears as a broad distribution of charge states between $1150 \mathrm{Th}$ and about $2000 \mathrm{Th}$, which cannot be resolved individually (Figure 5D). This broad curve is typical for extended, non-globular molecules and similar to 

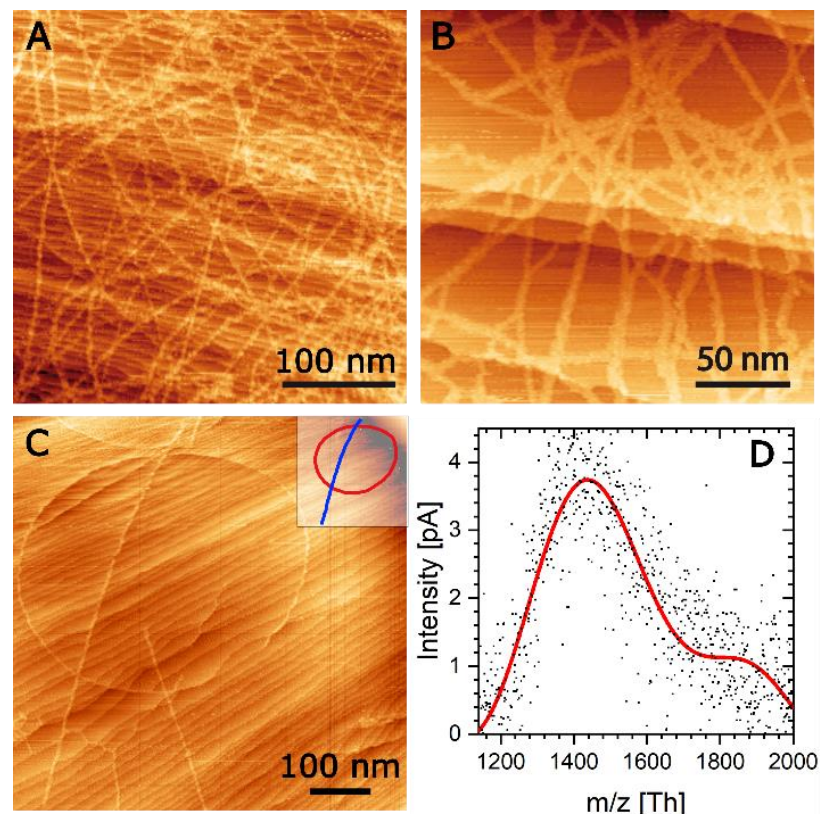

Figure 5. Deposition of plasmid DNA (pUC19, 1.7 MDa mass). A-C: RT-UHV-STM analysis on $\operatorname{Ag}(111)$. A) High coverage of multiple strands crossing ( $\mathrm{U}=1.3 \mathrm{~V} ; \mathrm{I}=90 \mathrm{pA})$. B) Close up view with helical twisted and supercoiled strands crossing step edges of the crystal $(\mathrm{U}=1.3 \mathrm{~V} ; \mathrm{I}=10 \mathrm{pA})$. C) Low coverage with two individual circular plasmids appearing as relaxed ring and supercoiled rod, respectively. Insert: Schematic of C). D) Mass spectrum of pUC19. Raw data (dots), guide-to-the-eye (red).

those obtained by others with related plasmid-type species using ESI-MS ${ }^{214}$. The $\mathrm{m} / \mathrm{z}$ center of gravity around 1500 Th translates into approximately 1100 elementary charges per DNA molecule. This is roughly 10-fold higher than expected for the maximal charging deduced from the Rayleigh limit ${ }^{188}$ for a globular molecule in an aqueous solution. This elevated number of charges, which is also experimentally determined by other groups using charge detection mass spectrometry on various DNA molecules ${ }^{215,216}$, indicates that the globular Rayleigh model seems not reasonable for rather elongated molecules. Assuming a cylindrical shape instead, the corresponding cylindrical Rayleigh limit of $1100 \mathrm{e}$ (details in SI) is consistent with the experimental results. The experimental maximum charging per molecule of $\sim 1500$ can be deduced from the actual $\mathrm{m} / \mathrm{z}$ lower boundary ( 1160). This value is higher than the Rayleigh limit would predict suggesting a kind of overcharging. Further, the number of phosphodiester residues assumed to carry the negative charges of DNA in solution (5372 in pUC19), obviously play a minor part in an ESI environment. For an attempt to interpret the apparent second population (the curve shoulder to the right of main peak in D) please refer to SI.

As a general consequence of the elongated appearance, transition from charged droplets produced by the ESI source, to single gas-phase ions very likely follow the chain ejection model (CEM), in contrast to the charge residue model (CRM) ${ }^{217}$ applicable for the previous test molecules.

For DNA-depositions ${ }^{195}$, the dQMS was operated in an RFonly mode at $1100 \mathrm{Th}$, i.e., cutting all masses below this threshold and transmitting all charge states attributed to pUC19. After high-density deposition circular plasmid DNA molecules appear as a quite crowded chaotic mesh, where single molecules are hardly be distinguished (Figure 5A, B). Higher resolved images on $\mathrm{Cu}(111)$ allow for a differentiation between helically twisted and supercoiled pUC19 (data not shown). Lower coverages evoke single species (Figure 5C). Here, the accurate geometric shapes are remarkable, in contrast to serpentine appearance at drop-casting ${ }^{218}$. This may be caused by the high number of charges on the molecule close to the cylindrical Rayleigh limit obtained during ESI process resulting in a high Coulomb repulsion and a balloon shape at the beginning of the landing process ${ }^{219}$ before discharging. No impurities are visible aside the clearly recognizable DNA molecules, which appear intact.

ES-CIBD Performance. The requirements for a soft-landing machine deviate from an established analytical mass spectrometer mainly by much higher intensities, but also by well-defined low kinetic energies of the ion beam. The $\mathrm{m} / \mathrm{z}$ range is important to investigate possibly interesting materials. The "total efficiency" of a preparative machine corresponds to the "sensitivity" of an analytical machine: While the high $\mathrm{m} / \mathrm{z}$ resolution $R$ is compulsive for an analytical machine, this ends up in a tradeoff with the beam intensity as the dominant parameter of a preparative machine. For the ES-CIBD system, the beam intensity even almost entirely depends on the ionization efficiency of the deposited molecules. However, transmisson efficiency and saturation in the ion guides are basically constant parameters of our frequency adapted hardware.

Table 1 Deposition parameters

\begin{tabular}{|lcccc|}
\hline Molecule & Rhodamine B & CuTCPP & Insulin & pUC19 \\
\hline Molecular weight & $443 \mathrm{Da}$ & $854 \mathrm{Da}$ & $5.8 \mathrm{kDa}$ & $1.7 \mathrm{MDa}$ \\
\hline Molarity $[\mathrm{M}]$ & $10^{-4}$ & $8 \cdot 10^{-5}$ & $8 \cdot 10^{-5}$ & $10^{-8}$ \\
\hline Sample current & $+2.2 \mathrm{nA}$ & $-0.4 \mathrm{nA}^{(1)}$ & $+0.4 \mathrm{nA}^{(1)}$ & $-0.4 \mathrm{nA}$ \\
\hline Spray eff. $=T_{E S I}$ & $12 \%$ & $1.4 \%$ & $3.2 \%$ & $20 \%$ \\
\hline Transmission eff. $=T_{\text {CIBD }}$ & \multicolumn{4}{c}{$22 \%$} \\
\hline Overall efficiency $^{(2)}=T_{\text {Total }}$ & $2.7 \%$ & $0.30 \%$ & $0.71 \%$ & $4.4 \%$ \\
\hline
\end{tabular}

(1) Current for one (main) peak determined, when multiple distinct peaks are present; here $[\mathrm{Cu}-\mathrm{TCCP}]^{2-},[\mathrm{Ins}]^{5+}$

(2) Overall efficiency including all analyte peaks if multiple are present

The currents listed in Table 1 depend on the concentration of the specimen in the sprayed solution, certainly among other parameters affecting the spray process. Mean values at the sample are obtained near the optimum parameters. The typical current at the capillary outlet is $10 \mathrm{nA}$ for Rhodamine B.

The amount of specimen transmitted through the CIBD system to the sample is expressed as the overall efficiency ${ }^{215-217}$ $T_{\text {Total }}=\frac{\text { Deposited molecules per } s}{\text { Sprayed molecules per } s}$. Other authors used the terms "overall soft-landing yield" $54,128,142,218$ or "total efficiency" ${ }^{141}$. $T_{\text {Total }}$ cannot be measured directly, the number and charge of molecules possibly generated by ESI, has to be known. This "utilization efficiency" depends strongly on the sprayed molecule ${ }^{224}$ and the construction of the ESI-source ${ }^{134,136}$. We refer to it as $T_{E S I}=\frac{\text { Current leaving capillary }}{\text { Charge of sprayed molecules per } \mathrm{s}}$. Combined with the transmission efficiency of the CIBD system downstream of the capillary, $T_{C I B D}=\frac{\text { Current at sample }}{\text { Current leaving capillary }}$, the overall efficiency is $T_{\text {Total }}=T_{E S I} \cdot T_{C I B D}$. Overall efficiencies are listed in Table 1 (see details in the SI).

For comparison, in 1977 Cooks $^{13}$ achieved a deposition current of $10 \mathrm{nA}$, mass-selected with $R=100$. Though he used an electron impact source, this early experiment is remarkable, as it demonstrates that the ion generation and the primary transfer into vacuum is limiting, not the capacities downstream. Mass-selected ESI spray started ${ }^{40,58,62,132,134,144-147,225}$ in the $21^{\text {th }}$ century, The Laskin group reports up to $-4.6 \mathrm{nA}$ for negative 
spray and $8.2 \mathrm{nA}$ for positive spray, respectively, in the same device $^{149}$.

According to literature, mass-selected overall efficiency $T_{\text {Total }}$ ranges from $10^{-5} \%$ to $1.6 \% \%^{58,59,132,133,136,146-148}$. Note the prevailing influence of the molecule as well as the different resolutions of the mass-selective devices, as listed in the SI. Furthermore, the diameter of the ESI emitter from $100 \mu \mathrm{m}$ down to $1 \mu \mathrm{m}$ (nano-spray) has substantial relevance to the overall efficiency. With decreasing droplet size (by use of smaller emitters), $T_{\text {Total }}$ increases. Assuming an optimized specimen concentration, the probability for a droplet containing no or multiple specimen molecules is reduced.

There is a tradeoff between resolution and transmission in any mass spectrometer. Moreover, the number of oscillations of an ion in the RF-field is crucial. Basically, our design allows to keep the number of oscillations of an ion constant during an $\mathrm{m} / \mathrm{z}$ scan. This is achieved by adapting the frequency versus kinetic energy, however this feature is not fully implemented yet. Transmission $T_{d Q M S}$ as a function of resolution $R$ is shown for Rhodamine B and Insulin for analysis as well as for deposition (c.f. Figure 6).

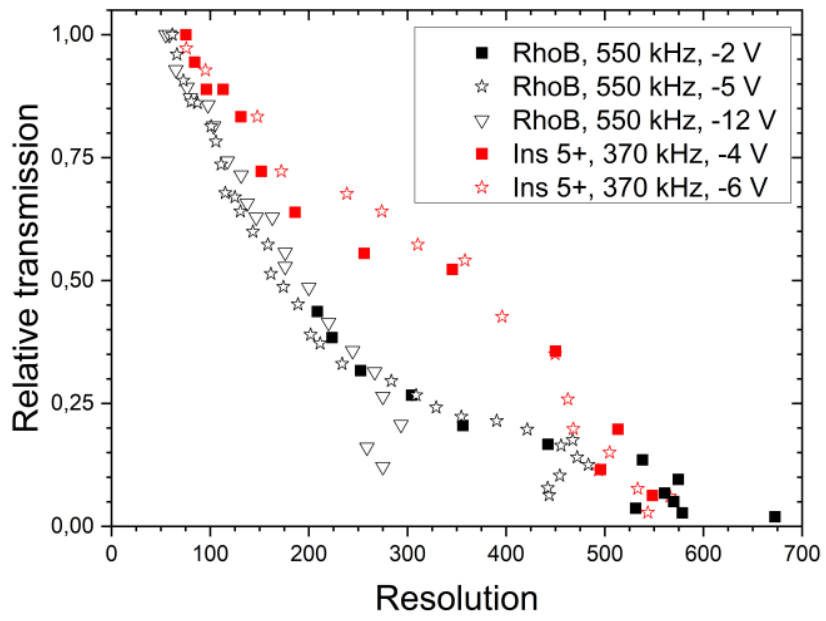

Figure 6. Resolution vs peak transmission of the dQMS. Data points are normalized with their corresponding highest transmission value. Test ions are the Rhodamine B cation and the Insulin 5+ ion (see Figure 2 and Figure 3). Operation frequencies of the $\mathrm{dQMS}$ and field axis potentials with respect to chamber $\mathrm{C}$ are given in the legend.

Soft-landing and reactive-landing demand a defined kinetic energy of molecules to be deposited, i.e., energy broadening is relevant. The mean landing energy may be changed via the sample potential versus kinetic energy of the ions which is defined in chamber C. Downstream, ions mean free path is too long. The deposition current as a function of the sample potential was exemplary recorded using $\mathrm{Cu}$-TCPP (Figure 7). The first derivative gives an energy broadening of about $2.2 \mathrm{~V}$ at FWHM. Thus, molecules with kinetic energies below $2 \mathrm{eV} / \mathrm{z}$ may be deposited with reasonable intensity, well below the soft-landing limit of about $10 \mathrm{eV} / \mathrm{z}$.

Finally, the measurement of the deposition current over time provides access to the amount of deposited charge, i.e., the number of landed molecules can be calculated through the charge state known from MS. This is a strong advantage compared to a thermal evaporation device like an OMBE.

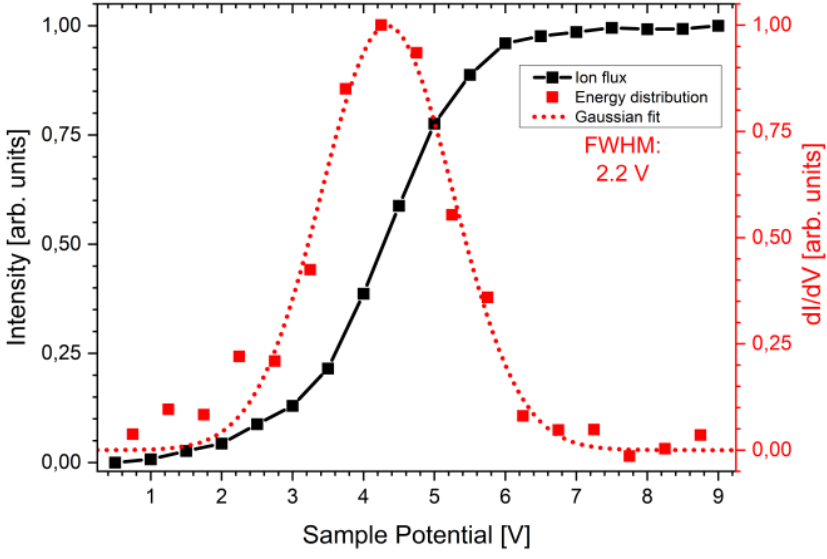

Figure 7. Kinetic energy of $\mathrm{Cu}-\mathrm{TCPP}$ molecules measured via ion flux as a function of sample potential. The derivative of the flux gives the energy distribution of the ions.

\section{SUMMARY AND OUTLOOK}

A versatile and efficient CIBD-system coupled to an ESI source is presented. It is proofed as a valuable tool to make a lot of species "fly" which are considered as not sublimable: small or simple organic molecules like Rhodamine B, the porphyrin derivative $\mathrm{Cu}$-TCPP, the larger biomolecules insulin and plasmid DNA with a mass of 1.7 MDa have been soft-landed, so as other molecules such as spermine ${ }^{195}$, ZnPC (data not shown), and nanocarbons like graphene nano-ribbons ${ }^{226}$, with no limits in sight.

In the components of this design, several innovative ideas were consequently implemented:

A) Tubes instead of standard aperture plates with a diameter as low as possible were inserted to connect two pressure stages. Thereby, the residual gas-load was greatly reduced. Coincidently, the transmission efficiency through the tubes is even enhanced, as the guiding RF-electrodes were continuously linked between the stages. There is no discontinuity like with an aperture plate. In the high-pressure regime this concept was realized by combining an ion-funnel with an ion-tunnel to form a TWIN ion guide, resulting in a reduction of gas-load by a factor of 20 compared to an aperture of same diameter. In the low-pressure regime, 16-pole wire ion guides with tiny clear diameters (SWIGs) are used, reducing gas-load by a factor of 10 . B) Low amplitude square wave RF signals, applied to all types of ion guides with steadily variable frequency allow for a transmission efficiency of typically $80 \%$ per ion guide for molecules of any $\mathrm{m} / \mathrm{z}$ in both pressure regimes.

C) The mass-selective dQMS device is operated with square wave RF signals as well. As in the ion guides, the steadily variable frequency results in a virtually unlimited $\mathrm{m} / \mathrm{z}$ range of the investigated and deposited molecules. The transmission at a given resolution is almost independent from the $\mathrm{m} / \mathrm{z}$ value of a molecule. A resolution up to 150 provides high transmission efficiencies $>75 \%$. Reasonable precise selection with a resolution of above 500 still provides $10-15 \%$ transmission. The tiny beam diameter of the injecting SWIG combined with the small radial beam energy results in a high injection probability into the dQMS translating into a high overall transmission of the whole CIBD-system.

The chosen design results in:

1) A low energy distribution of about $2 \mathrm{eV} / \mathrm{z}$ (Figure 7) allowing for soft-landing.

2) A high deposition current up to $2.2 \mathrm{nA}$ (Table 1). 
3) A transmission efficiency of about $22 \%$ over a virtually unlimited range of $\mathrm{m} / \mathrm{z}$ combined with a mass resolution up to $R=$ 650 (Figure 6).

4) A high overall efficiency up to $4.4 \%$ (Table 1).

5) A high degree of system compactness and pumping efficiency combined with a low background pressure below $10^{-10}$ mbar and high cleanliness (Figure 1).

We want to emphasize that possibly cruising neutrals along the line of sight to the sample, which is often discussed, can be excluded from the STM images and from the tiny diameter of the guides. This design implicitly prevents a straight line of sight.

To our best knowledge, resolution, overall efficiency and mass range are above values reported for deposition systems in literature (see discussion in the SI).

The described CIBD design reflects the pilot development stage. Clear diameters of the ion guides, their tunnel length and operating pressure will be optimized further. From the current point of view at least chamber E might be omitted without deteriorating the pressure level in sample chamber F (Figure 1). Attaching alternate beam sources like a cluster source will unlock further applications.

\section{ASSOCIATED CONTENT}

\section{Supporting Information}

The Supporting Information is available free of charge on the ACS Publications website.

TOC: Instrumental settings and parameters (Section 1-2, Fig S1); calculation of insulin adducts (Section 2, Fig S2); calculation of cylindrical Rayleigh limit (Section 4, Fig. S3); overall efficiency benchmarking (Section 5, Fig. S4); typical CIBD parameters RhoB (section 6); experimental details and references (section 7-9); (pdf).

\section{AUTHOR INFORMATION}

\section{Corresponding Author}

* Johannes V. Barth - Physics-Department E20, Technical

University of Munich, 85748 Garching, Germany;

orcid.org/0000-0002-6270-2150. Email: jvb@tum.de

* Hartmut Schlichting - Physics-Department E20, Technical

University of Munich, 85748 Garching, Germany;

orcid.org/ 0000-0001-6421-5076;

Email: hartmut.schlichting@tum.de

\section{ACKNOWLEDGMENT}

This work was supported by the ERC Advanced Grant MolArt \#247299, the ERC-PoC Grant Softbeam \#780907, the FET Innovation Launchpad Grant MolShuttle \#946223, and the FET-Open Grant 2D Ink \# 664878. The team is supported by the e-conversion project. In the one-decade long ES-CIBD development history a number of bachelor, master and $\mathrm{PhD}$ students contributed to this success, mainly: Tobias Kaposi, Michael Walz, Sabrina Sterzl, Theresa Buberl, Nicolo Sernicola and David Reinisch. We gratefully thank Peter Knecht, Anthoula Papageorgiou and Joachim Reichert for their support with the STM.

\section{REFERENCES}

(1) Trimpin, S.; Marshall, D. D.; Karki, S.; Madarshahian, S.; Hoang, K.; Meher, A. K.; Pophristic, M.; Richards, A. L.; Lietz, C. B.; Fischer, J. L.; Elia, E. A.; Wang, B.; Pagnotti, V. S.; Lutomski, C. A.; El-Baba, T. J.; Lu, I.-C.; Wager-Miller, J.; Mackie, K.; McEwen, C. N.; Inutan, E. D.: An Overview of Biological Applications and Fundamentals of New Inlet and Vacuum Ionization Technologies, Rapid Com. Mass Spectrom. 2020, 35, e8829, doi:10.1002/rcm.8829. (2) Gross, J. H.: Mass Spectrometry A Textbook 3rd Edition; Gross, J. H., Ed.; Springer, 2017, doi:10.1007/978-3-319-54398-7.
(3) Takats, Z.; Wiseman, J. M.; Gologan, B.; Cooks, R. G.: Mass Spectrometry Sampling Under Ambient Conditions with Desorption Electrospray Ionization, Science 2004, 306, 471, doi:10.1126/science.1104404.

(4) Cooks, R. G.; Ouyang, Z.; Takats, Z.; Wiseman, J. M.: Ambient Mass Spectrometry, Science 2006, 311, 1566, doi:10.1126/science.1119426.

(5) Monge, M. E.; Harris, G. A.; Dwivedi, P.; Fernandez, F. M.: Mass Spectrometry: Recent Advances in Direct Open Air Surface Sampling / Ionization, Chem. Rev. 2013, 113, 2269,

doi:10.1021/cr300309q.

(6) Verbeck, G.; Hoffmann, W.; Walton, B.: Soft-Landing Preparative Mass Spectrometry, Analyst 2012, 137, 4393,

doi:10.1039/c2an35550g.

(7) Laskin, J.; Johnson, G. E.; Warneke, J.; Prabhakaran, V.: From Isolated Ions to Multilayer Functional Materials Using Ion Soft Landing, Angew. Chem. 2018, 57 (50), 16270-16284,

doi:10.1002/anie.201712296.

(8) Krumbein, L.; Anggara, K.; Stella, M.; Michnowicz, T.; Ochner, H.; Abb, S.; Rinke, G.; Portz, A.; Dürr, M.; Schlickum, U.; Baldwin, A.; Floris, A.; Kern, K.; Rauschenbach, S.: Fast Molecular Compression by a Hyperthermal Collision Gives Bond-Selective Mechanochemistry, Phys. Rev. Lett. 2021, 126 (5), 056001,

doi:10.1103/PhysRevLett.126.056001.

(9) Anggara, K.; Zhu, Y.; Delbianco, M.; Rauschenbach, S.; Abb, S.; Seeberger, P. H.; Kern, K.: Exploring the Molecular Conformation Space by Soft Molecule Surface Collision, J. Am. Chem. Soc. 2020, 142 (51), 21420-21427, doi:10.1021/jacs.0c09933.

(10) Berggren, K. K.; Bard, A.; Wilbur, J. L.; Gillaspy, J. D.; Helg, A. G.; McClelland, J. J.; Rolston, S. L.; Phillips, W. D.; Prentiss, M.; Whitesides, G. M.: Microlithography by Using Neutral Metastable Atoms and Self-Assembled Monolayers, Science 1995, 269 (5228), 1255-1257, doi:10.1126/science.7652572.

(11) Watt, F.; Bettiol, A. A.; Kan, J. A. V.; Teo, E. J.; Breese, M. B. H.: Ion Beam Lithography and Nanofabrication: A Review, Int. J. Nanosci. 2005, 4 (03), 269-286, doi:10.1142/S0219581X05003139. (12) Drost, M.; Tu, F.; Berger, L.; Preischl, C.; Zhou, W.; Gliemann, H.; Wöll, C.; Marbach, H.: Surface-Anchored Metal-Organic Frameworks as Versatile Resists for Gas-Assisted E-Beam Lithography: Fabrication of Sub-10 Nanometer Structures, ACS Nano 2018, 12

(4), 3825-3835, doi:10.1021/acsnano.8b01071.

(13) Franchetti, V.; Solka, B. H.; Baitinger, W. E.; Amy, J. W.; Cooks, R. G.: Soft Landing of Ions As a Means of Surface Modification, Int. J. Mass Spectrom. Ion Phys. 1977, 23, 29-35, doi:10.1016/0020-7381(77)80004-1.

(14) Pradeep, T.; Feng, B.; Ast, T.; Patrick, J. S.; Cooks, R. G.; Pachuta, S. J.: Chemical Modification of Fluorinated Self-Assembled Monolayer Surfaces by Low Energy Reactive Ion Bombardment, $J$. Am. Soc. Mass. Spectrom. 1995, 6 (3), 187-194, doi:10.1016/10440305(94)00110-L.

(15) Miller, S. A.; Luo, H.; Pachuta, S. J.; Cooks, R. G.: Soft-Landing of Polyatomic Ions at Fluorinated Self-Assembled Monolayer Surfaces, Science 1997, 275, 1447-1450, doi:10.1126/science.275.5305.1447.

(16) Luo, H.; Miller, S. A.; Cooks, R. G.; Pachuta, S. J.: Soft Landing of Polyatomic Ions for Selective Modification of Fluorinated SelfAssembled Monolayer Surfaces, Int. J. Mass Spectrom. Ion Processes 1998, 174 (1-3), 193-217, doi:10.1016/S01681176(97)00302-9.

(17) Feng, B.; Wunschel, D. S.; Masselon, C. D.; Pasa-Tolic, L.; Smith, R. D.: Retrieval of DNA Using Soft-Landing after Mass Analysis by ESI-FTICR for Enzymatic Manipulation, J. Am. Chem. Soc. 1999, 121 (38), 8961-8962, doi:10.1021/ja9923888.

(18) Cyriac, J.; Pradeep, T.; Kang, H.; Souda, R.; Cooks, R. G.: LowEnergy Ionic Collisions at Molecular Solids, Chem. Rev. 2012, 112 (10), 5356-5411, doi:10.1021/cr200384k.

(19) Laskin, J.; Denisov, E. V.; Shukla, A. K.; Barlow, S. E.; Futrell, J. H.: Surface-Induced Dissociation in a Fourier Transform Ion Cyclotron Resonance Mass Spectrometer: Instrument Design and Evaluation, Anal. Chem. 2002, 74 (14), 3255-3261,

doi:10.1021/ac025514q. 
(20) Alvarez, J.; Cooks, R. G.; Barlow, S. E.; Gaspar, D. J.; Futrell, J. H.; Laskin, J.: Preparation and in Situ Characterization of Surfaces Using Soft Landing in a Fourier Transform Ion Cyclotron Resonance Mass Spectrometer, Anal. Chem. 2005, 77 (11), 3452-3460, doi: $10.1021 / \mathrm{ac} 0481349$.

(21) Gologan, B.; Green, J. R.; Alvarez, J.; Laskin, J.; Cooks, R. G.: Ion / Surface Reactions and Ion Soft-Landing, Phys. Chem. Chem. Phys. 2005, 7, 1490, doi:10.1039/b418056a.

(22) Wang, P.; Hadjar, O.; Gassman, P. L.; Laskin, J.: Reactive Landing of Peptide Ions on Self-Assembled Monolayer Surfaces: An Alternative Approach for Covalent Immobilization of Peptides on Surfaces, Phys. Chem. Chem. Phys. 2008, 10 (11), 1512-1522, doi:10.1039/b717617a.

(23) Johnson, G. E.; Lysonski, M.; Laskin, J.: In Situ Reactivity and TOF-SIMS Analysis of Surfaces Prepared by Soft and Reactive Landing of Mass-Selected Ions, Anal. Chem. 2010, 82 (13), 57185727, doi:10.1021/ac100734g.

(24) Johnson, G. E.; Laskin, J.: Preparation of Surface Organometallic Catalysts by Gas-Phase Ligand Stripping and Reactive Landing of Mass-Selected Ions, Chem. Eur. J. 2010, 16 (48), 14433-14438, doi:10.1002/chem.201002292.

(25) Laskin, J.: Ion-Surface Collisions in Mass Spectrometry: Where Analytical Chemistry Meets Surface Science, Int. J. Mass Spectrom. 2015, 377, 188-200, doi:10.1016/j.ijms.2014.07.004.

(26) Johnson, G. E.; Gunaratne, D.; Laskin, J.: Soft- and Reactive Landing of Ions onto Surfaces: Concepts and Applications, Mass Spectrom. Rev. 2015, 35 (3), 439-479, doi:10.1002/mas.21451. (27) Jacobs, D. C.: Reactive Collisions of Hyperthermal Energy Molecular Ions with Solid Surfaces, Annu. Rev. Phys. Chem. 2002, 53 (1), 379-407, doi:10.1146/annurev.physchem.53.100301.131622. (28) Mikhailov, V. A.; Mize, T. H.; Benesch, J. L. P.; Robinson, C. V.: Mass-Selective Soft-Landing of Protein Assemblies with Controlled Landing Energies, Anal. Chem. 2014, 86 (16), 8321-8328, doi:10.1021/ac5018327.

(29) Kahle, S.; Deng, Z.; Malinowski, N.; Tonnoir, C.; Forment-Aliaga, A.; Thontasen, N.; Rinke, G.; Le, D.; Turkowski, V.; Rahman, T. S.; Rauschenbach, S.; Ternes, M.; Kern, K.: The Quantum Magnetism of Individual Manganese-12-Acetate Molecular Magnets Anchored at Surfaces, Nano Lett. 2011, 12 (1), 518-521,

doi: $10.1021 / \mathrm{nl} 204141 \mathrm{z}$.

(30) Nagaoka, S.; Matsumoto, T.; Ikemoto, K.; Mitsui, M.; Nakajima, A.: Soft-Landing Isolation of Multidecker V2(Benzene)3Complexes in an Organic Monolayer Matrix: An Infrared Spectroscopy and Thermal Desorption Study, J. Am. Chem. Soc. 2007, 129 (6), 1528 1529, doi:10.1021/ja068442j.

(31) Peng, W.-P.; Johnson, G. E.; Fortmeyer, I. C.; Wang, P.; Hadjar, O.; Cooks, R. G.; Laskin, J.: Redox Chemistry in Thin Layers of Organometallic Complexes Prepared Using Ion Soft Landing, Phys. Chem. Chem. Phys. 2011, 13, 267-275, doi:10.1039/c0cp01457e. (32) Hauptmann, N.; Hamann, C.; Tang, H.; Berndt, R.: Soft-Landing Electrospray Deposition of the Ruthenium Dye N3 on Au(111), $J$. Chem. Phys. 2013, 117 (19), 9734-9738, doi:10.1021/jp311420d.

(33) Pepi, F.; Ricci, A.; Tata, A.; Favero, G.; Frasconi, M.; Noci, S. D.; Mazzei, F.: Soft Landed Protein Voltammetry, Chem. Commun. 2007, 2007 (33), 3494, doi:10.1039/b705668k.

(34) Wijesundara, M. B. J.; Fuoco, E.; Hanley, L.: Preparation of Chemical Gradient Surfaces by Hyperthermal Polyatomic Ion Deposition: A New Method for Combinatorial Materials Science, Langmuir 2001, 17 (19), 5721-5726, doi:10.1021/la010592e.

(35) Shen, J.; Yim, Y. H.; Feng, B.; Grill, V.; Evans, C.; Cooks, R. G.: Soft Landing of Ions onto Self-Assembled Hydrocarbon and Fluorocarbon Monolayer Surfaces, Int. J. Mass Spectrom. 1999, 182, 423-435, doi:10.1016/S1387-3806(98)14251-3.

(36) Qin, X.; Tzvetkov, T.; Jacobs, D. C.: Reaction of 5-40 EV Ions with Self-Assembled Monolayers, J. Phys. Chem. A 2006, 110 (4), 1408-1415, doi:10.1021/jp054596u.

(37) Klipp, B.; Grass, M.; Müller, J.; Stolcic, D.; Lutz, U.; Ganteför, G.; Schlenker, T.; Boneberg, J.; Leiderer, P.: Deposition of Mass-Selected Cluster Ions Using a Pulsed Arc Cluster-Ion Source, Appl. Phys. A 2001, 73 (5), 547-554, doi:10.1007/s003390100947.
(38) Palmer, R. E.; Pratontep, S.; Boyen, H.-G.: Nanostructured Surfaces from Size-Selected Clusters, Nat. Mater. 2003, 2 (7), 443-448, doi:10.1038/nmat897.

(39) Heiz, U.; Bullock, E. L.: Fundamental Aspects of Catalysis on Supported Metal Clusters, J. Mater. Chem. 2004, 14, 564, doi: $10.1039 / \mathrm{b} 313560 \mathrm{~h}$.

(40) Rauschenbach, S.; Stadler, F. L.; Lunedei, E.; Malinowski, N.; Koltsov, S.; Costantini, G.; Kern, K.: Electrospray Ion Beam Deposition of Clusters and Biomolecules, Small 2006, 2 (4), 540-547, doi:10.1002/smll.200500479.

(41) Vajda, S.; White, M. G.: Catalysis Applications of Size-Selected Cluster Deposition, ACS Catal. 2015, 5 (12), 7152-7176,

doi:10.1021/acscatal.5b01816.

(42) Laskin, J.; Johnson, G. E.; Prabhakaran, V.: Soft Landing of Complex Ions for Studies in Catalysis and Energy Storage, J. Phys. Chem. C 2016, 120 (41), 23305-23322,

doi:10.1021/acs.jpcc.6b06497.

(43) Vats, N.; Wang, Y.; Sen, S.; Szilagyi, S.; Ochner, H.; Abb, S.; Burghard, M.; Sigle, W.; Kern, K.; Aken, P. A. van; Rauschenbach, S.: Substrate-Selective Morphology of Cesium Iodide Clusters on Graphene, ACS Nano 2020, 14 (4), 4626-4635,

doi:10.1021/acsnano.9b10053.

(44) Kaden, W. E.; Wu, T.; Kunkel, W. A.; Anderson, S. L.: Electronic Structure Controls Reactivity of Size-Selected Pd Clusters Adsorbed on TiO2 Surfaces, Science 2009, 326 (5954), 826-829, doi:10.1126/science.1180297.

(45) Tyo, E. C.; Vajda, S.: Catalysis by Clusters with Precise Numbers of Atoms, Nat. Nanotechnol. 2015, 10 (7), 577-588,

doi:10.1038/nnano.2015.140.

(46) Ha, M.-A.; Baxter, E. T.; Cass, A. C.; Anderson, S. L.; Alexandrova, A. N.: Boron Switch for Selectivity of Catalytic Dehydrogenation on Size-Selected Pt Clusters on Al2O3, J. Am. Chem. Soc. 2017, 139 (33), 11568-11575, doi:10.1021/jacs.7b05894.

(47) Xu, J.; Murphy, S.; Xiong, D.; Cai, R.; Wei, X.-K.; Heggen, M.; Barborini, E.; Vinati, S.; Dunin-Borkowski, R. E.; Palmer, R. E.; Liu, L.: Cluster Beam Deposition of Ultrafine Cobalt and Ruthenium Clusters for Efficient and Stable Oxygen Evolution Reaction, ACS Appl. Energy Mater. 2018, 1 (7), 3013-3018,

doi:10.1021/acsaem.8b00111.

(48) Boettcher, A.; Weis, P.; Jester, S.-S.; Loeffler, D.; Bihlmeier, A.; Klopper, W.; Kappes, M. M.: Solid C58 Films, Phys. Chem. Chem. Phys. 2005, 7, 2816, doi:10.1039/b505703e.

(49) Dubey, G.; Urcuyo, R.; Abb, S.; Rinke, G.; Burghard, M.;

Rauschenbach, S.; Kern, K.: Chemical Modification of Graphene via Hyperthermal Molecular Reaction, J. Am. Chem. Soc. 2014, 136 (39), 13482-13485, doi:10.1021/ja5046499.

(50) Pepi, F.; Tata, A.; Garzoli, S.; Giacomello, P.; Ragno, R.; Patsilinakos, A.; Fusco, M. D.; D’Annibale, A.; Cannistraro, S.; Baldacchini, C.; Favero, G.; Frasconi, M.; Mazzei, F.: Chemically Modified Multiwalled Carbon Nanotubes Electrodes with Ferrocene Derivatives through Reactive Landing, J. Phys. Chem. C 2011, 115 (11), 4863-4871, doi:10.1021/jp1100472.

(51) Stützel, E. U.; Dufaux, T.; Sagar, A.; Rauschenbach, S.; Balasubramanian, K.; Burghard, M.; Kern, K.: Spatially Resolved Photocurrents in Graphene Nanoribbon Devices, Appl. Phys. Lett. 2013, 102, 43106, doi:10.1063/1.4789850.

(52) Rinke, G.; Rauschenbach, S.; Schrettl, S.; Hoheisel, T. N.; Blohm, J.; Gutzler, R.; Rosei, F.; Frauenrath, H.; Kern, K.: SoftLanding Electrospray Ion Beam Deposition of Sensitive Oligoynes on Surfaces in Vacuum, Int. J. Mass Spectrom. 2015, 377, 228-234, doi:10.1016/j.ijms.2014.06.026.

(53) Fodor, S.; Read, J.; Pirrung, M.; Stryer, L.; Lu, A.; Solas, D.: Light-Directed, Spatially Addressable Parallel Chemical Synthesis, Science 1991, 251 (4995), 767-773, doi:10.1126/science.1990438. (54) Zhu, H.; Bilgin, M.; Bangham, R.; Hall, D.; Casamayor, A.; Bertone, P.; Lan, N.; Jansen, R.; Bidlingmaier, S.; Houfek, T.; Mitchell, T.; Miller, P.; Dean, R. A.; Gerstein, M.; Snyder, M.: Global Analysis of Protein Activities Using Proteome Chips, Science 2001, 293 (5537), 2101-2105, doi:10.1126/science.1062191.

(55) Reineke, U.; Volkmer-Engert, R.; Schneider-Mergener, J.: Applications of Peptide Arrays Prepared by the SPOT-Technology, 
Curr. Opin. Biotechnol. 2001, 12 (1), 59-64, doi:10.1016/S09581669(00)00178-6.

(56) Reimer, U.; Reineke, U.; Schneider-Mergener, J.: Peptide Arrays: From Macro to Micro, Curr. Opin. Biotechnol. 2002, 13 (4), 315-320, doi:10.1016/S0958-1669(02)00339-7.

(57) Wong, L. S.; Khan, F.; Micklefield, J.: Selective Covalent Protein Immobilization: Strategies and Applications, Chem. Rev. 2009, 109 (9), 4025-4053, doi:10.1021/cr8004668.

(58) Ouyang, Z.; Takats, Z.; Blake, T. A.; Gologan, B.; Guymon, A. J.; Wiseman, J. M.; Oliver, J. C.; Davisson, V. J.; Cooks, R. G.: Preparing Protein Microarrays by Soft-Landing of Mass-Selected Ions, Science 2003, 301, 1351-1354, doi:10.1126/science.1088776.

(59) Blake, T. A.; Ouyang, Z.; Wiseman, J. M.; Takats, Z.; Guymon, A. J.; Kothari, S.; Cooks, R. G.: Preparative Linear Ion Trap Mass Spectrometer for Separation and Collection of Purified Proteins and Peptides in Arrays Using Ion Soft Landing, Anal. Chem. 2004, 76 (21), 6293-6305, doi:10.1021/ac048981b.

(60) Wang, P.; Laskin, J.: Helical Peptide Arrays on Self-Assembled Monolayer Surfaces through Soft and Reactive Landing of Mass-Selected Ions, Angew. Chem. 2008, 47 (35), 6678-6680,

doi:10.1002/anie.200801366.

(61) Laskin, J.; Hu, Q.: Reactive Landing of Gramicidin S and Ubiquitin Ions onto Activated Self-Assembled Monolayer Surfaces, $J$. Am. Soc. Mass Spectrom. 2017, 28 (7), 1304-1312,

doi:10.1007/s13361-017-1614-2.

(62) Hamann, C.; Woltmann, R.; Hong, I.-P.; Hauptmann, N.; Karan, S.; Berndt, R.: Ultrahigh Vacuum Deposition of Organic Molecules by Electrospray Ionization, Rev. Sci. Instrum. 2011, 82, 33903, doi: $10.1063 / 1.3553010$.

(63) Hu, Q.; Laskin, J.: Secondary Structures of Ubiquitin Ions SoftLanded onto Self-Assembled Monolayer Surfaces, J. Phys. Chem. B 2016, 120 (22), 4927-4936, doi:10.1021/acs.jpcb.6b02448.

(64) Abb, S.; Tarrat, N.; Cortes, J.; Andriyevsky, B.; Harnau, L.; Schön, J. C.; Rauschenbach, S.; Kern, K.: Carbohydrate Self-Assembly at Surfaces: STM Imaging of Sucrose Conformation and Ordering on $\mathrm{Cu}(100)$, Angew. Chem. 2019, 58 (25), 8336-8340,

doi:10.1002/anie.201901340.

(65) Wu, X.; Delbianco, M.; Anggara, K.; Michnowicz, T.; PardoVargas, A.; Bharate, P.; Sen, S.; Pristl, M.; Rauschenbach, S.; Schlickum, U.; Abb, S.; Seeberger, P. H.; Kern, K.: Imaging Single Glycans, Nature 2020, 582 (7812), 375-378, doi:10.1038/s41586-0202362-1.

(66) Anggara, K.; Zhu, Y.; Fittolani, G.; Yu, Y.; Tyrikos-Ergas, T.; Delbianco, M.; Rauschenbach, S.; Abb, S.; Seeberger, P. H.; Kern, K.: Identifying the Origin of Local Flexibility in a Carbohydrate Polymer, PNAS 2021, 118 (23), e2102168118, doi:10.1073/pnas.2102168118.

(67) Paul, W.; Steinwedel, H.: A New Mass Spectrometer without a Magnetic Field, Z. Naturforsch. A 1953, 8 (7), 448-450, doi:10.1515/zna-1953-0710.

(68) Paul, W.; Raether, M.: Das Elektrische Massenfilter, Z. Phys. 1955, 140 (3), 262-273, doi:10.1007/BF01328923.

(69) Paul, W.; Reinhard, H. P.; Zahn, U. von.: Das Elektrische Massenfilter Als Massenspektrometer Und Isotopentrenner, Z. Phys. 1958, 152 (2), 143-182, doi:10.1007/BF01327353.

(70) Zahn, U. V.: Monopole Spectrometer, a New Electric Field Mass Spectrometer, Rev. Sci. Instrum. 1963, 34 (1), 1-4,

doi:http://dx.doi.org/10.1063/1.1718110.

(71) Gerlich, D.: Experimental Investigations of Ion-Molecule Reactions Relevant to Interstellar Chemistry, J. Chem. Soc., Faraday Trans. 1993, 89 (13), 2199-2208, doi:10.1039/FT9938902199.

(72) Dzhonson, A.; Gerlich, D.; Bieske, E. J.; Maier, J. P.: Apparatus for the Study of Electronic Spectra of Collisionally Cooled Cations: Para-Dichlorobenzene, J. Mol. Struct. 2006, 795 (1-3), 93-97, doi:10.1016/j.molstruc.2005.11.044.

(73) Otto, R.; Hlavenka, P.; Trippel, S.; Mikosch, J.; Singer, K.; Weidemüller, M.; Wester, R.: How Can a 22-Pole Ion Trap Exhibit Ten Local Minima in the Effective Potential?, J. Phys. B: At., Mol. Opt. Phys. 2009, 42 (15), 154007, doi:10.1088/0953-4075/42/15/154007. (74) Lorenz, U. J.; Rizzo, T. R.: Planar Multipole Ion Trap/Time-ofFlight Mass Spectrometer, Anal. Chem. 2011, 83 (20), 7895-7901, doi:10.1021/ac201790d.
(75) Asvany, O.; Bielau, F.; Moratschke, D.; Krause, J.; Schlemmer, S.: Note: New Design of a Cryogenic Linear Radio Frequency Multipole Trap, Rev. Sci. Instrum. 2010, 81 (7), 76102,

doi:10.1063/1.3460265.

(76) Hayashi, T.: Quadrupole Field in Circular Concave Electrodes, Rev. Sci. Instrum. 1968, 39 (7), 958-961, doi:10.1063/1.1683577.

(77) Dawson, P. H.; Whetten, N. R.: Quadrupole Mass Filter: Circular Rods and Peak Shapes, J. Vac. Sci. Technol. 1970, 7 (3), 440441, doi:10.1116/1.1492892.

(78) Denison, D. R.: Operating Parameters of a Quadrupole in a Grounded Cylindrical Housing, J. Vac. Sci. Technol. 1971, 8 (1), 266-269, doi:10.1116/1.1316304.

(79) Lee-Whiting, G. E.; Yamazaki, L.: Semi-Analytical Calculations For Circular Quadrupoles, Nucl. Instrum. Methods 1971, 94 (2), 319-332, doi:10.1016/0029-554X(71)90587-8.

(80) Pearce, C. G.; Halsall, D.: A Quadrupole Mass Filter with Flat Electrodes, Int. J. Mass Spectrom. Ion Phys. 1978, 27 (1), 31-41, doi:10.1016/0020-7381(78)80099-0.

(81) Beaty, E. C.: Simple Electrodes for Quadrupole Ion Traps, J. Appl. Phys. 1987, 61 (6), 2118-2122, doi:10.1063/1.337968.

(82) Hunter, K. L.; Mcintosh, B. J.: An Improved Model of the Fringing Fields of a Quadrupole Mass Filter, Int. J. Mass Spectrom. Ion Processes 1989, 087 (2), 157-164, doi:10.1016/0168-

1176(89)80019-9.

(83) Gerlich, D.: Inhomogeneous Rf Fields: A Versatile Tool for the Study of Processes with Slow Ions, Adv. Chem. Phys. 1992, 82, 671, doi:10.1002/9780470141397.ch1.

(84) Schulte, J.; Shevchenko, P. V.; Radchik, A. V.: Nonlinear Field Effects in Quadrupole Mass Filters, Rev. Sci. Instrum. 1999, 70 (9), 3566-3571, doi:http://dx.doi.org/10.1063/1.1149960.

(85) Gibson, J. R.; Taylor, S.: Prediction of Quadrupole Mass Filter Performance for Hyperbolic and Circular Cross Section Electrodes, Rapid Commun. Mass Spectrom. 2000, 14 (18), 1669-1673, doi:10.1002/1097-0231(20000930)14:18<1669::AID-

RCM80>3.0.CO;2-\#.

(86) Gibson, J. R.; Taylor, S.: Numerical Investigation of the Effect of Electrode Size on the Behaviour of Quadrupole Mass Filters, Rapid Commun. Mass Spectrom. 2001, 15 (20), 1960-1964, doi:10.1002/rcm.469.

(87) Gibson, J. R.; Taylor, S.: Asymmetrical Features of Mass Spectral Peaks Produced by Quadrupole Mass Filters, Rapid Commun. Mass Spectrom. 2003, 17 (10), 1051-1055, doi:10.1002/rcm.1017. (88) Ding, C.; Konenkov, N. V.; Douglas, D. J.: Quadrupole Mass Filters with Octopole Fields, Rapid Commun. Mass Spectrom. 2003, 17 (22), 2495-2502, doi:10.1002/rcm.1235.

(89) Konenkov, N.; Londry, F.; Ding, C.; Douglas, D. J.: Linear Quadrupoles with Added Hexapole Fields, J. Am. Soc. Mass. Spectrom. 2006, 17 (8), 1063-1073, doi:10.1016/j.jasms.2006.03.013. (90) Salazar, G. A.; Masujima, T.: Computer Simulations of a New Three Rods Ion Optic (TRIPOLE) with High Focusing and Mass Filtering Capabilities, J. Am. Soc. Mass. Spectrom. 2007, 18 (3), 413421, doi:10.1016/j.jasms.2006.10.007.

(91) Moradian, A.; Douglas, D. J.: Mass Selective Axial Ion Ejection from Linear Quadrupoles with Added Octopole Fields, J. Am. Soc. Mass Spectrom. 2008, 19 (2), 270-280,

doi:10.1016/j.jasms.2007.10.025.

(92) Douglas, D. J.: Linear Quadrupoles in Mass Spectrometry, Mass Spectrom. Rev. 2009, 28 (6), 937-960, doi:10.1002/mas.20249.

(93) Xiao, Z.; Zhao, X.; Douglas, D. J.: Quadrupole Mass Filters with Added Hexapole Fields, Rapid Commun. Mass Spectrom. 2010, 24 (14), 1985-1992, doi:10.1002/rcm.4596.

(94) Zhou, X.; Xiong, C.; Xu, G.; Liu, H.; Tang, Y.; Zhu, Z.; Chen, R.; Qiao, H.; Tseng, Y.-H.; Peng, W.-P.; Nie, Z.; Chen, Y.: Potential Distribution and Transmission Characteristics in a Curved Quadrupole Ion Guide, J. Am. Soc. Mass. Spectrom. 2011, 22 (2), 386-398, doi:10.1007/s13361-010-0045-0.

(95) Douglas, D. J.; Konenkov, N. V.: Mass Resolution of Linear Quadrupole Ion Traps with Round Rods, Rapid Commun. Mass Spectrom. 2014, 28 (21), 2252-2258, doi:10.1002/rcm.7018. (96) Shaffer, S. A.; Tang, K.; Anderson, G. A.; Prior, D. C.; Udseth, H. R.; Smith, R. D.: A Novel Ion Funnel for Focusing Ions at Elevated Pressure Using Electrospray Ionization Mass Spectrometry, 
Rapid Commun. Mass Spectrom. 1997, 11 (16), 1813-1817, doi:10.1002/(SICI)1097-0231(19971030)11:16<1813::AIDRCM87>3.0.CO;2-D

(97) Shaffer, S. A.; Prior, D. C.; Anderson, G. A.; Udseth, H. R.; Smith, R. D.: An Ion Funnel Interface for Improved Ion Focusing and Sensitivity Using Electrospray Ionization Mass Spectrometry, Anal. Chem. 1998, 70 (19), 4111-4119, doi:10.1021/ac9802170. (98) Shaffer, S. A.; Tolmachev, A.; Prior, D. C.; Anderson, G. A.; Udseth, H. R.; Smith, R. D.: Characterization of an Improved Electrodynamic Ion Funnel Interface for Electrospray Ionization Mass Spectrometry, Anal. Chem. 1999, 71 (15), 2957-2964,

doi:10.1021/ac990346w.

(99) Tolmachev, A. V.; Udseth, H. R.; Smith, R. D.: Charge Capacity Limitations of Radio Frequency Ion Guides in Their Use for Improved Ion Accumulation and Trapping in Mass Spectrometry, Anal. Chem. 2000, 72 (5), 970-978, doi:10.1021/ac990729u.

(100) Kim, T.; Tang, K.; Udseth, H. R.; Smith, R. D.: A Multicapillary Inlet Jet Disruption Electrodynamic Ion Funnel Interface for Improved Sensitivity Using Atmospheric Pressure Ion Sources, Anal. Chem. 2001, 73 (17), 4162-4170, doi:10.1021/ac010174e.

(101) Tang, K.; Shvartsburg, A. A.; Lee, H.-N.; Prior, D. C.; Buschbach, M. A.; Li, F.; Tolmachev, A. V.; Anderson, G. A.; Smith, R. D.: High-Sensitivity Ion Mobility Spectrometry / Mass Spectrometry Using Electrodynamic Ion Funnel Interfaces, Anal. Chem. 2005, 77 (10), 3330-3339, doi:10.1021/ac048315a.

(102) Page, J. S.; Tolmachev, A. V.; Tang, K.; Smith, R. D.: Variable Low-Mass Filtering Using an Electrodynamic Ion $\mathrm{f}$ Unnel, J. Mass Spectrom. 2005, 40 (9), 1215-1222, doi:10.1002/jms. 900.

(103) R. Bahr, E. T., D. Gerlich.: Ring Electrode Ion Guide, Verh. Deutsch. Phys. Ges. (IV) 1969, 4, 343.

(104) Teloy, E.; Gerlich, D.: Integral Cross Sections for Ion-Molecule Reactions. 1. The Guided Beam Technlque, Chem. Phys. 1974, 4 (3), 417-427, doi:10.1016/0301-0104(74)85008-1.

(105) Gerlich, D.; Kaefer, G.: Ion Trap Studies of Association Processes in Collisions of $\mathrm{CH} 3+$ and $\mathrm{Cd} 3+$ with $\mathrm{N}-\mathrm{H} 2$, p-H2, D2, and $\mathrm{He}$ at $80 \mathrm{~K}$, Astrophys. J. 1989, 347, 849, doi:10.1086/168174. (106) Guan, S.; G.Marshall, A.: Stacked-Ring Electrostatic Ion Guide, J. Am. Soc. Mass. Spectrom. 1996, 7 (1), 101-106, doi:10.1016/1044-0305(95)00605-2.

(107) Swarbrick, J. C.; Taylor, J. B.; O'Shea, J. N.: Electrospray Deposition in Vacuum, Appl. Surf. Sci. 2006, 252 (15), 5622-5626, doi:10.1016/j.apsusc.2005.12.025

(108) Satterley, C. J.; Perdigao, L. M. A.; Saywell, A.; Magnano, G.; Rienzo, A.; Mayor, L. C.; Dhanak, V. R.; Beton, P. H.; O'Shea, J. N.: Electrospray Deposition of Fullerenes in Ultra-High Vacuum: In Situ Scanning Tunneling Microscopy and Photoemission Spectroscopy, Nanotechnology 2007, 18, 455304, doi:10.1088/09574484/18/45/455304.

(109) Mayor, L. C.; Taylor, J. B.; Magnano, G.; Rienzo, A.; Satterley, C. J.; O'Shea, J. N.; Schnadt, J.: Photoemission, Resonant Photoemission, and X-Ray Absorption of a Ru(Ii) Complex Adsorbed on Rutile TiO2(110) Prepared by in Situ Electrospray Deposition, $J$. Chem. Phys. 2008, 129, 114701, doi:10.1063/1.2975339.

(110) Tanaka, H.; Kawai, T.: Scanning Tunneling Microscopy Imaging and Manipulation of DNA Oligomer Adsorbed on $\mathrm{Cu}(111)$ Surfaces by a Pulse Injection Method, J. Vac. Sci. Technol. B 1997, 15, 602, doi:10.1116/1.589299.

(111) Yamada, T.; Shinohara, H.; Maofa, G.; Mashiko, S.; Kimura, K.: A Molecular-Beam Apparatus with a Spray-Jet Technique for Studying Neutral Non-Volatile Molecules, Chem. Phys. Lett. 2003, 370 (1-2), 132-138, doi:10.1016/S0009-2614(03)00060-5.

(112) Grill, L.; Stass, I.; Rieder, K.-H.; Moresco, F.: Preparation of Self-Ordered Molecular Layers by Pulse Injection, Surf. Sci. 2006, 600 (11), L143-L147, doi:10.1016/j.susc.2006.03.040.

(113) Yamada, T.; Shinohara, H.; Kamikado, T.; Mashiko, S.: SprayJet Technique for Studying Nonvolatile Functional Molecules: Comparison of Different Spray-Jet Inlet Systems, Jpn. J. Appl. Phys. 2008, 47 (2), 1408-1411, doi:10.1143/JJAP.47.1408.

(114) Kitching, K. J.; Lee, H.-N.; Elam, W. T.; Johnston, E. E.; MacGregor, H.; Miller, R. J.; Turecek, F.; Ratner, B. D.: Development of an Electrospray Approach to Deposit Complex Molecules on Plasma
Modified Surfaces, Rev. Sci. Instrum. 2003, 74 (11), 4832-4839, doi:10.1063/1.1618013.

(115) Volny, M.; Elam, W. T.; Branca, A.; Ratner, B. D.; Turecek, F.: Preparative Soft and Reactive Landing of Multiply Charged Protein Ions on a Plasma-Treated Metal Surface, Anal. Chem. 2005, 77 (15), 4890-4896, doi:10.1021/ac0507136.

(116) Volny, M.; Elam, W. T.; Ratner, B. D.; Turecek, F.: Preparative Soft and Reactive Landing of Gas-Phase Ions on Plasma-Treated Metal Surfaces, Anal. Chem. 2005, 77 (15), 4846-4853, doi:10.1021/ac0505019.

(117) Clemmons, J. H.; Herrero, F. A.: Mass Spectroscopy Using a Rotating Electric Field, Rev. Sci. Instrum. 1998, 69 (6), 2285-2291, doi:10.1063/1.1148933.

(118) Nojima, M.; Anai, Y.; Hotta, M.; Kurumi, S.; Suzuki, K.; Adachi, T.; Kusanagi, T.; Moritani, K.: Development of a Mass Spectrometer Using Two Rotating Electric Fields, J. Vac. Sci. Technol. B 2016, 34 (3), 03H132, doi:10.1116/1.4944838.

(119) Su, P.; Espenship, M. F.; Laskin, J.: Principles of Operation of a Rotating Wall Mass Analyzer for Preparative Mass Spectrometry, J. Am. Soc. Mass Spectrom. 2020, 31 (9), 1875-1884,

doi:10.1021/jasms.0c00140.

(120) Su, P.; Hu, H.; Unsihuay, D.; Zhang, D.; Dainese, T.; Diaz, R. E.; Lee, J.; Gunaratne, D. K.; Wang, H.; Maran, F.; Mei, J.; Laskin, J.: Preparative Mass Spectrometry Using a Rotating-Wall Mass Analyzer, Angew. Chem. 2020, 132 (20), 7785-7790,

doi:10.1002/ange.202000065.

(121) Foret, F.; Zhou, H.; Gangl, E.; Karger, B. L.: Subatmospheric Electrospray Interface for Coupling of Microcolumn Separations with Mass Spectrometry, Electrophoresis 2000, 21 (7), 1363-1371, doi:10.1002/(SICI)1522-2683(20000401)21:7<1363::AID-

ELPS1363>3.0.CO;2-U.

(122) Page, J. S.; Tang, K.; Kelly, R. T.; Smith, R. D.: Subambient Pressure Ionization with Nanoelectrospray Source and Interface for Improved Sensitivity in Mass Spectrometry, Anal. Chem. 2008, 80, 1800-1805, doi:10.1021/ac702354b.

(123) Gamero-Castano, M.: The Structure of Electrospray Beams in Vacuum, J. Fluid Mech. 2008, 604, 339-368, doi:10.1017/S0022112008001316.

(124) Marginean, I.; Page, J. S.; Tolmachev, A. V.; Tang, K.; Smith, R. D.: Achieving 50\% Ionization Efficiency in Subambient Pressure Ionization with Nanoelectrospray, Anal. Chem. 2010, 82 (22), 9344 9349, doi:10.1021/ac1019123.

(125) Cox, J. T.; Marginean, I.; Kelly, R. T.; Smith, R. D.; Tang, K.: Improving the Sensitivity of Mass Spectrometry by Using a New Sheath Flow Electrospray Emitter Array at Subambient Pressures, $J$. Am. Soc. Mass. Spectrom. 2014, 25 (12), 2028-2037, doi:10.1007/s13361-014-0856-5.

(126) Debatin, M.; Kröner, M.; Mikosch, J.; Trippel, S.; Morrison, N.; Reetz-Lamour, M.; Woias, P.; Wester, R.; Weidemüller, M.: Planar Multipole Ion Trap, Phys. Rev. A 2008, 77 (3), 33422,

doi:10.1103/PhysRevA.77.033422.

(127) Tolmachev, A. V.; Webb, I. K.; Ibrahim, Y. M.; Garimella, S. V. B.; Zhang, X.; Anderson, G. A.; Smith, R. D.: Characterization of Ion Dynamics in Structures for Lossless Ion Manipulations, Anal. Chem. 2014, 86 (18), 9162-9168, doi:10.1021/ac502054p.

(128) Attah, I. K.; Garimella, S. V. B.; Webb, I. K.; Nagy, G.; Norheim, R. V.; Schimelfenig, C. E.; Ibrahim, Y. M.; Smith, R. D.: Dual Polarity Ion Confinement and Mobility Separations, J. Am. Soc. Mass Spectrom. 2019, 30 (6), 967-976, doi:10.1007/s13361-01902138-1.

(129) Rulison, A. J.; Flagan, R. C.: Scale-up of Electrospray Atomization Using Linear Arrays of Taylor Cones, Rev. Sci. Instrum. 1993, 64 (3), 683-686, doi:10.1063/1.1144197.

(130) Sen, A. K.; Darabi, J.; Knapp, D. R.: Simulation and Parametric Study of a Novel Multi-Spray Emitter for ESI-MS Applications, Microfluid. Nanofluid. 2006, 3 (3), 283-298, doi:10.1007/s10404006-0122-7.

(131) Page, J. S.; Kelly, R. T.; Tang, K.; Smith, R. D.: Ionization and Transmission Efficiency in an Electrospray Ionization-Mass Spectrometry Interface, J. Am. Soc. Mass. Spectrom. 2007, 18 (9), 15821590, doi:10.1016/j.jasms.2007.05.018. 
(132) Mayer, P. S.; Turecek, F.; Lee, H.-N.; Scheidemann, A. A.; Olney, T. N.; Schumacher, F.; Strop, P.; Smrcina, M.; Patek, M.; Schirlin, D.: Preparative Separation of Mixtures by Mass Spectrometry, Anal. Chem. 2005, 77 (14), 4378-4384, doi:10.1021/ac050444j. (133) Yang, X.; Mayer, P. S.; Turecek, F.: Preparative Separation of a Multicomponent Peptide Mixture by Mass Spectrometry, J. Mass Spectrom. 2006, 41 (2), 256-262, doi:10.1002/jms.986.

(134) Pauly, M.; Sroka, M.; Reiss, J.; Rinke, G.; Albarghash, A.; Vogelgesang, R.; Hahne, H.; Kuster, B.; Sesterhenn, J.; Kern, K.; Rauschenbach, S.: A Hydrodynamically Optimized Nano-Electrospray Ionization Source and Vacuum Interface, Analyst 2014, 139, 1856, doi:10.1039/c3an01836a.

(135) Bernier, L.; Pinfold, H.; Pauly, M.; Rauschenbach, S.; Reiss, J.: Gas Flow and Ion Transfer in Heated ESI Capillary Interfaces, J. Am. Soc. Mass. Spectrom. 2018, 29 (4), 761-773, doi:10.1007/s13361018-1895-0.

(136) Bernier, L.; Taesch, M.; Rauschenbach, S.; Reiss, J.: Transfer Conditions and Transmission Bias in Capillaries of Vacuum Interfaces, Int. J. Mass Spectrom. 2019, 447, 116239,

doi:10.1016/j.ijms.2019.116239.

(137) Tang, K.; Tolmachev, A. V.; Nikolaev, E.; Zhang, R.; Belov, M. E.; Udseth, H. R.; Smith, R. D.: Independent Control of Ion Transmission in a Jet Disrupter Dual-Channel Ion Funnel Electrospray Ionization MS Interface, Anal. Chem. 2002, 74 (20), 54315437, doi:10.1021/ac0202583.

(138) Deng, L.; Chen, X.; Li, W.; Wang, Z.; Wong, Y. E.; Chan, T.W. D.: Sensitivity and Robustness Enhancements by Using a VShape Ion Funnel in FTICR-MS, Anal. Chem. 2015, 87 (16), 80738077, doi:10.1021/acs.analchem.5b01828.

(139) Goldby, I. M.; Issendorff, B. von; Kuipers, L.; Palmer, R. E.: Gas Condensation Source for Production and Deposition of Size-Selected Metal Clusters, Rev. Sci. Instrum. 1997, 68 (9), 3327-3334, doi:10.1063/1.1148292.

(140) Hamann, C.: An Electrospray Ion Source for Ultra-High Vacuum Deposition of Organic Molecules, PhD-Thesis, Christian-Albrechts-Universität zu Kiel, 2011.

(141) Heiz, U.; Vanolli, F.; Trento, L.; Schneider, W.-D.: Chemical Reactivity of Size-Selected Supported Clusters: An Experimental Setup, Rev. Sci. Instrum. 1997, 68 (5), 1986-1994, doi:10.1063/1.1148113.

(142) Hadjar, O.; Wang, P.; Futrell, J. H.; Dessiaterik, Y.; Zhu, Z.; Cowin, J. P.; Iedema, M. J.; Laskin, J.: Design and Performance of an Instrument for Soft Landing of Biomolecular Ions on Surfaces, Anal. Chem. 2007, 79 (17), 6566-6574, doi:10.1021/ac070600h. (143) Hadjar, O.; Futrell, J. H.; Laskin, J.: First Observation of Charge Reduction and Desorption Kinetics of Multiply Protonated Peptides Soft Landed onto Self-Assembled Monolayer Surfaces, $J$. Phys. Chem. C 2007, 111 (49), 18220-18225,

doi:10.1021/jp075293y.

(144) Laskin, J.; Wang, P.; Hadjar, O.: Soft-Landing of Peptide Ions onto Self-Assembled Monolayer Surfaces: An Overview, Phys. Chem. Chem. Phys. 2008, 10, 1079-1090, doi:10.1039/b712710c. (145) Kern, B.; Greisch, J.-F.; Strelnikov, D.; Weis, P.; Boettcher, A.; Ruben, M.; Schaefer, B.; Schooss, D.; Kappes, M. M.: Photoluminescence Spectroscopy of Mass-Selected Electrosprayed Ions Embedded in Cryogenic Rare-Gas Matrixes, Anal. Chem. 2015, 87 (23), 11901-11906, doi:10.1021/acs.analchem.5b03491.

(146) Gunaratne, K. D. D.; Prabhakaran, V.; Ibrahim, Y. M.; Norheim, R. V.; Johnson, G. E.; Laskin, J.: Design and Performance of a High-Flux Electrospray Ionization Source for Ion Soft Landing, Analyst 2015, 140 (9), 2957-2963, doi:10.1039/c5an00220f.

(147) Peng, W.-P.; Goodwin, M. P.; Nie, Z.; Volny, M.; Ouyang, Z.; Cooks, R. G.: Ion Soft Landing Using a Rectilinear Ion Trap Mass Spectrometer, Anal. Chem. 2008, 80 (17), 6640-6649, doi:10.1021/ac800929w.

(148) Nie, Z.; Li, G.; Goodwin, M. P.; Gao, L.; Cyriac, J.; Cooks, R. G.: In Situ SIMS Analysis and Reactions of Surfaces Prepared by Soft Landing of Mass-Selected Cations and Anions Using an Ion Trap Mass Spectrometer, J. Am. Soc. Mass. Spectrom. 2009, 20 (6), 949-956, doi:10.1016/j.jasms.2009.02.019.

(149) Su, P.; Hu, H.; Warneke, J.; Belov, M. E.; Anderson, G. A.; Laskin, J.: Design and Performance of a Dual-Polarity Instrument for
Ion Soft Landing, Anal. Chem. 2019, 91 (9), 5904-5912, doi:10.1021/acs.analchem.9b00309.

(150) Kurulugama, R. T.; Belov, M. E.: Orthogonal Ion Injection Apparatus and Process, Patent 2014, No. US 8,698,075 B2, US $8,698,075$ B2.

(151) Chen, T.-C.; Fillmore, T. L.; Prost, S. A.; Moore, R. J.; Ibrahim, Y. M.; Smith, R. D.: Orthogonal Injection Ion Funnel Interface Providing Enhanced Performance for Selected Reaction MonitoringTriple Quadrupole Mass Spectrometry, Anal. Chem. 2015, 87 (14), 7326-7331, doi:10.1021/acs.analchem.5b01482.

(152) Su, P.; Chen, X.; Smith, A. J.; Espenship, M. F.; Oviedo, H. Y. S.; Wilson, S. M.; Gholipour-Ranjbar, H.; Larriba-Andaluz, C.; Laskin, J.: Multiplexing of Electrospray Ionization Sources Using Orthogonal Injection into an Electrodynamic Ion Funnel, Anal. Chem. 2021, 93 (33), 11576-11584, doi:10.1021/acs.analchem.1c02092. (153) Marshall, A. G.; Schweikhard, L.: Fourier Transform Ion Cyclotron Resonance Mass Spectrometry: Technique Developments, Int. J. Mass Spectrom. Ion Processes 1992, 118-119, 37-70, doi:10.1016/0168-1176(92)85058-8.

(154) Hu, Q.; Noll, R. J.; Li, H.; Makarov, A.; Hardman, M.; Cooks, R. G.: The Orbitrap: A New Mass Spectrometer, J. Mass Spectrom. 2005, 40 (4), 430-443, doi:10.1002/jms.856.

(155) Perry, R. H.; Cooks, R. G.; Noll, R. J.: Orbitrap Mass Spectrometry: Instrumentation, Ion Motion and Applications, Mass Spectrom. Rev. 2008, 27 (6), 661-699, doi:10.1002/mas.20186.

(156) Michalski, A.; Damoc, E.; Lange, O.; Denisov, E.; Nolting, D.; Müller, M.; Viner, R.; Schwartz, J.; Remes, P.; Belford, M.; Dunyach, J.-J.; Cox, J.; Horning, S.; Mann, M.; Makarov, A.: Ultra High Resolution Linear Ion Trap Orbitrap Mass Spectrometer (Orbitrap Elite) Facilitates Top Down LC MS/MS and Versatile Peptide Fragmentation Modes, Mol. Cell. Proteomics 2011, 11 (3), 1-11, doi:10.1074/mcp.O111.013698.

(157) Pratontep, S.; Carroll, S. J.; Xirouchaki, C.; Streun, M.; Palmer, R. E.: Size-Selected Cluster Beam Source Based on Radio Frequency Magnetron Plasma Sputtering and Gas Condensation, Rev. Sci. Instrum. 2005, 76, 45103, doi:10.1063/1.1869332.

(158) Pauly, M.; Sroka, M.; Reiss, J.; Rinke, G.; Albarghash, A.; Vogelgesang, R.; Hahne, H.; Kuster, B.; Sesterhenn, J.; Kern, K.; Rauschenbach, S.: A Hydrodynamically Optimized Nano-Electrospray Ionization Source and Vacuum Interface, Analyst 2014, 139, 1856, doi:10.1039/c3an01836a.

(159) Kelly, R. T.; Tolmachev, A. V.; Page, J. S.; Tang, K.; Smith, R. D.: The Ion Funnel: Theory, Implementations, and Applications, Mass Spectrom. Rev. 2009, 29, 294-312, doi:10.1002/mas.20232. (160) Ibrahim, Y. M.; Baker, E. S.; Danielson, W. F.; Norheim, R. V.; Prior, D. C.; Anderson, G. A.; Belov, M. E.; Smith, R. D.: Development of a New Ion Mobility Time-of-Flight Mass Spectrometer, Int. J. Mass Spectrom. 2015, 377, 655-662,

doi:10.1016/j.ijms.2014.07.034.

(161) Ford, M. J.; Kertesz, V.; Berkel, G. J. V.: Thin-Layer Chromatography/Electrospray Ionization Triple-Quadrupole Linear Ion Trap Mass Spectrometry System: Analysis of Rhodamine Dyes Separated on Reversed-Phase C8 Plates, J. Mass Spectrom. 2005, 40 (7), 866875, doi:10.1002/jms.796.

(162) Yamada, T.; Shinohara, H.; Mashiko, S.: Improvement of the Inlet System for the Spray-Jet Technique for Use in Spectroscopic Studies and Molecular Deposition, Thin Solid Films 2006, 499 (1-2), 44-48, doi:10.1016/j.tsf.2005.07.033.

(163) Volny, M.; Sengupta, A.; Wilson, C. B.; Swanson, B. D.; Davis, E. J.; Turecek, F.: Surface-Enhanced Raman Spectroscopy of Soft-Landed Polyatomic Ions and Molecules, Anal. Chem. 2007, 79 (12), 4543-4551, doi:10.1021/ac070278a.

(164) Wortmann, A.; Kistler-Momotova, A.; Zenobi, R.; Heine, M. C.; Wilhelm, O.; Pratsinis, S. E.: Shrinking Droplets in Electrospray Ionization and Their Influence on Chemical Equilibria, J. Am. Soc. Mass. Spectrom. 2007, 18 (3), 385-393,

doi:10.1016/j.jasms.2006.10.010.

(165) Rauschenbach, S.; Vogelgesang, R.; Malinowski, N.; Gerlach, J. W.; Benyoucef, M.; Costantini, G.; Deng, Z.; Thontasen, N.; Kern, K.: Electrospray Ion Beam Deposition: Soft-Landing and Fragmentation of Functional Molecules at Solid Surfaces, ACS Nano 2009, 3 (10), 2901-2910, doi:10.1021/nn900022p. 
(166) Law, W. S.; Wang, R.; Hu, B.; Berchtold, C.; Meier, L.; Chen, H.; Zenobi, R.: On the Mechanism of Extractive Electrospray Ionization, Anal. Chem. 2010, 82 (11), 4494-4500, doi:10.1021/ac100390t. (167) Cyriac, J.; Wleklinski, M.; Li, G.; Gao, L.; Cooks, R. G.: In Situ Raman Spectroscopy of Surfaces Modified by Ion Soft Landing, Analyst 2012, 137 (6), 1363, doi:10.1039/C2AN16163J.

(168) Clemen, M.; Gernert, C.; Peters, J.; Grotemeyer, J.: Fragmentation Reactions of Labeled and Unlabeled Rhodamine B in a HighResolution Fourier Transform Ion Cyclotron Resonance Mass Spectrometer, Eur. J. Mass Spectrom. 2013, 19 (2), 135-139,

doi:10.1255/ejms.1216.

(169) Bluck, L.; Volmer, D. A.: The Role of Naturally Occurring Stable Isotopes in MassSpectrometry, Part I: The Theory, Spectroscopy Springfield 2009, 23, 36-.

(170) Bluck, L.; Volmer, D. A.: The Role of Naturally Occurring Stable Isotopes in MassSpectrometry, Part II: The Instrumentation, Spectroscopy Springfield 2009, 23, 50-

(171) Geiger, R. J.; Melnyk, M. C.; Busch, K. L.; Bartlett, M. G.: Modifications to an Analytical Mass Spectrometer for the Soft-Landing Experiment, Int. J. Mass Spectrom. 1999, 182, 415-422, doi:10.1016/S1387-3806(98)14262-8.

(172) Benesch, J. L. P.; Ruotolo, B. T.; Simmons, D. A.; Barrera, N. P.; Morgner, N.; Wang, L.; Saibil, H. R.; Robinson, C. V.: Separating and Visualising Protein Assemblies by Means of Preparative Mass Spectrometry and Microscopy, J. Struct. Biol. 2010, 172 (2), 161-168, doi:10.1016/j.jsb.2010.03.004.

(173) PubChem Compound Summary for CID 118984375.: Insulin Human - Compound Summary, National Center for Biotechnology Information 2021, doi:https://pubchem.ncbi.nlm.nih.gov/compound/118984375.

(174) P01308.: UniProtKB Human Insulin, Nucleic Acids Res. 2021, 49, D1, doi:https://www.uniprot.org/uniprot/P01308.

(175) Derewenda, U.; Derewenda, Z.; Dodson, G. G.; Hubbard, R. E.; Korber, F.: Molecular Structure of Insulin: The Insulin Monomer and Its Assembly, Br. Med. Bull. 1989, 45 (1), 4-18, doi:10.1093/oxfordjournals.bmb.a072320.

(176) Pekar, A. H.; Frank, B. H.: Conformation of Proinsulin. Comparison of Insulin and Proinsulin Self-Association at Neutral PH, Biochemistry 1972, 11 (22), 4013-4016, doi:10.1021/bi00772a001.

(177) Nettleton, E. J.; Tito, P.; Sunde, M.; Bouchard, M.; Dobson, C. M.; Robinson, C. V.: Characterization of the Oligomeric States of Insulin in Self-Assembly and Amyloid Fibril Formation by Mass Spectrometry, Biophys. J. 2000, 79 (2), 1053-1065, doi:10.1016/S00063495(00)76359-4.

(178) Attri, A. K.; Fernandez, C.; Minton, A. P.: PH-Dependent SelfAssociation of Zinc-Free Insulin Characterized by ConcentrationGradient Static Light Scattering, Biophys. Chem. 2010, 148 (1-3), 28-33, doi:10.1016/j.bpc.2010.02.002.

(179) Lin, M.; Larive, C. K.: Detection of Insulin Aggregates with Pulsed-Field Gradient Nuclear Magnetic Resonance Spectroscopy., Anal. Biochem. 1995, 229, 214-220.

(180) Kadima, W.; Roy, M.; Lee, R. W.-K.; Kaarsholmj, N. C.; Dunn, M. F.: Studies of the Association and Conformational Properties of Metal-Free Insulin in Alkaline Sodium Chloride Solutions by One- and Two-Dimensional 'H NMR', J. Biol. Chem. 1992, 267, 8963-8970.

(181) Dunn, M. F.: Zinc-Ligand Interactions Modulate Assembly and Stability of the Insulin Hexamer - A Review, BioMetals 2005, 18 (4), 295-303, doi:10.1007/s10534-005-3685-y.

(182) Attri, A. K.; Fernandez, C.; Minton, A. P.: Self-Association of Zn-Insulin at Neutral PH: Investigation by Concentration Gradient-

Static and Dynamic Light Scattering, Biophys. Chem. 2010, 148 (13), 23-27, doi:10.1016/j.bpc.2010.02.001.

(183) Kadima, W.; Ogendal, L.; Bauer, R.; Kaarsholm, N.;

Brodersen, K.; Hansen, J. F.; Porting, P.: The Influence of Ionic Strength and PH on the Aggregation Properties of Zinc-Free Insulin Studied by Static and Dynamic Laser Light Scattering, Biopolymers 1993, 33 (11), 1643-1657, doi:10.1002/bip.360331103.

(184) Rahuel-Clermont, S.; French, C. A.; Kaarsholm, N. C.; Dunn, M. F.: Mechanisms of Stabilization of the Insulin Hexamer through Allosteric Ligand Interactions $\dagger$, Biochemistry 1997, 36 (19), 58375845, doi:10.1021/bi963038q.
(185) Kumar, A.; Venkatesu, P.: Prevention of Insulin Self-Aggregation by a Protic Ionic Liquid, $R S C A d v .2013,3$ (2), 362-367, doi:10.1039/c2ra22277a.

(186) Kaltashov, I. A.; Mohimen, A.: Estimates of Protein Surface Areas in Solution by Electrospray Ionization Mass Spectrometry, Anal. Chem. 2005, 77, 5370, doi:10.1021/ac050511+.

(187) Schmidt, A.; Karas, M.; Dülcks, T.: Effect of Different Solution Flow Rates on Analyte Ion Signals in Nano-ESI MS, or: When Does ESI Turn into Nano-ESI?, J. Am. Soc. Mass Spectrom. 2003, 14 (5), 492-500, doi:10.1016/S1044-0305(03)00128-4.

(188) Rayleigh, Lord.: On The Equilibrium Of Liquid Conducting Masses Charged With Electricity, Philos. Mag. 1882, 14, 184-186, doi:10.1080/14786448208628425.

(189) Bonvin, G.; Rudaz, S.; Schappler, J.: In-Spray Supercharging of Intact Proteins by Capillaryelectrophoresis-Electrospray Ionization-Mass Spectrometry Usingsheath Liquid Interface, Anal. Chim. Acta 2014, 813, 97-105, doi:10.1016/j.aca.2013.12.043.

(190) Susa, A. C.; Xia, Z.; Williams, E. R.: Small Emitter Tips for Native Mass Spectrometry of Proteins and Protein Complexes from Nonvolatile Buffers That Mimic the Intracellular Environment, Anal. Chem. 2017, 89 (5), 3116-3122, doi:10.1021/acs.analchem.6b04897. (191) Hu, J.; Guan, Q.-Y.; Wang, J.; Jiang, X.-X.; Wu, Z.-Q.; Xia, X.-H.; Xu, J.-J.; Chen, H.-Y.: Effect of Nanoemitters on Suppressing the Formation of Metal Adduct Ions in Electrospray Ionization Mass Spectrometry, Anal. Chem. 2017, 89 (3), 1838-1845,

doi:10.1021/acs.analchem.6b04218.

(192) Fabris, D.; Fenselau, C.: Characterization of Allosteric Insulin Hexamers by Electrospray Ionization Mass Spectrometry, Anal. Chem. 1999, 71 (2), 384-387, doi:10.1021/ac980753s.

(193) Rauschenbach, S.: Sodium and Potassium Ions Are Typical Satellites in MS, Private Comm. 2020.

(194) Raja, U. K. B.; Injeti, S.; Culver, T.; McCabe, J. W.; Angel, L. A.: Probing the Stability of Insulin Oligomers Using Electrospray Ionization Ion Mobility Mass Spectrometry, Eur. J. Mass Spectrom. 2015, 21 (6), 759-774, doi:10.1255/ejms.1396.

(195) Stoiber, K. A.: Investigating Molecules at Surfaces - from Preparative Mass Spectrometry of Large Biomolecules to Complex Desorption Kinetics, PhD-Thesis, Technische Uni München, 2021. (196) Otsuki, J.: STM Studies on Porphyrins, Coord. Chem. Rev. 2010, 254 (19-20), 2311-2341, doi:10.1016/j.ccr.2009.12.038. (197) Auwärter, W.; Ecija, D.; Klappenberger, F.; Barth, J. V.: Porphyrins at Interfaces, Nat. Chem. 2015, 7 (2), 105-120, doi:10.1038/nchem.2159.

(198) Zhao, M.; Wang, Y.; Ma, Q.; Huang, Y.; Zhang, X.; Ping, J.; Zhang, Z.; Lu, Q.; Yu, Y.; Xu, H.; Zhao, Y.; Zhang, H.: Ultrathin 2D Metal-Organic Framework Nanosheets, Advanced Materials 2015, 27 (45), 7372-7378, doi:10.1002/adma.201503648.

(199) Zhao, M.; Huang, Y.; Peng, Y.; Huang, Z.; Ma, Q.; Zhang, H.: Two-Dimensional Metal-Organic Framework Nanosheets: Synthesis and Applications, Chem. Soc. Rev. 2018, 47 (16), 6267-6295, doi:10.1039/C8CS00268A.

(200) Baig, N.; Kammakakam, I.; Falath, W.: Nanomaterials: A Review of Synthesis Methods, Properties, Recent Progress, and Challenges, Materials Advances 2021, 2 (6), 1821-1871,

doi:10.1039/D0MA00807A.

(201) Nicholls, D.; McKinzie, W. P.; Oncel, N.: 5-(Octadecyloxy) Isophthalic Acid-Assisted Copper(II) Meso-Tetra (4-Carboxyphenyl) Porphyrin Adsorption on Highly Ordered Pyrolytic Graphite, $J$. Phys. Chem. C 2010, 114 (35), 14983-14985,

doi:10.1021/jp104491t.

(202) Jöhr, R.; Hinaut, A.; Pawlak, R.; Sadeghi, A.; Saha, S.; Goedecker, S.; Such, B.; Szymonski, M.; Meyer, E.; Glatzel, T.: Characterization of Individual Molecular Adsorption Geometries by Atomic Force Microscopy: Cu-TCPP on Rutile TiO2 (110), J. Chem. Phys. 2015, 143 (9), 094202, doi:10.1063/1.4929608.

(203) Freund, S.; Hinaut, A.; Marinakis, N.; Constable, E. C.; Meyer, E.; Housecroft, C. E.; Glatzel, T.: Comparing a Porphyrin- and a Coumarin-Based Dye Adsorbed on $\mathrm{NiO}(001)$, Beilstein J. Nanotechnol. 2019, 10, 874-881, doi:10.3762/bjnano.10.88.

(204) Hinaut, A.; Pawlak, R.; Meyer, E.; Glatzel, T.: Electrospray Deposition of Organic Molecules on Bulk Insulator Surfaces, 
Beilstein J. Nanotechnol. 2015, 6, 1927-1934, doi:10.3762/bjnano.6.195.

(205) Günther, C.; Karl, N.; Pflaum, J.; Strohmaier, R.; Gompf, B.; Eisenmenger, W.; Müller, M.; Müllen, K.: LEED, STM, and TDS Studies of Ordered Thin Films of the Rhombus-Shaped Polycondensed Aromatic Hydrocarbon C54H22, on MoS2, GeS, and Graphite, Langmuir 2004, 21 (2), 656-665, doi:10.1021/la048009s.

(206) Davie, E.; Morris, J. H.; Smith, W. E.: Electron-Impact and Thermal Degradation of Rhodamine F5G Chloride and Related Compounds, Org. Mass Spectrom. 1974, 9 (8), 763-773,

doi:10.1002/oms.1210090805.

(207) Knecht, P.: Private Communication: Cu-TCPP Disintegrates upon OMBE Deposition, CO2 Peak in MS, Private Communication 2019.

(208) Deng, Z.; Thontasen, N.; Malinowski, N.; Rinke, G.; Harnau, L.; Rauschenbach, S.; Kern, K.: A Close Look at Proteins: Submolecular Resolution of Two- and Three-Dimensionally Folded Cytochrome c at Surfaces, Nano Lett. 2012, 12, 2452,

doi: $10.1021 / \mathrm{nl} 3005385$.

(209) Vats, N.; Rauschenbach, S.; Sigle, W.; Sen, S.; Abb, S.; Portz, A.; Dürr, M.; Burghard, M.; Aken, P. A. van; Kern, K.: Electron Microscopy of Polyoxometalate Ions on Graphene by Electrospray Ion Beam Deposition, Nanoscale 2018, 10 (10), 4952-4961,

doi:10.1039/c8nr00402a.

(210) Rajabi, K.; Ashcroft, A. E.; Radford, S. E.: Mass Spectrometric Methods to Analyze the Structural Organization of Macromolecular Complexes, Methods 2015, 89, 13-21,

doi:10.1016/j.ymeth.2015.03.004.

(211) Fremerey, J. K.: Residual Gas: Traditional Understanding and New Experimental Results, Vacuum 1999, 53 (1-2), 197-201, doi:10.1016/S0042-207X(98)00386-8.

(212) Yanisch-Perron, C.; Vieira, J.; Messing, J.: Improved M13 Phage Cloning Vectors and Host Strains: Nucleotide Sequences of the M13mpl8 and PUC19 Vectors, Gene 1985, 33 (1), 103-119, doi:10.1016/0378-1119(85)90120-9.

(213) Nordheim, A.; Knippers, R.; Dröge, P.; Meister, G.; Schiebel, E.; Vingron, M.; Walter, J.: Molekulare Genetik; Nordheim, A., Knippers, R., Eds.; Thieme Verlag KG, 2018, doi:ISBN 978-3-13242637-5.

(214) Cheng, X.; Camp, D. G.; Wu, Q.; Bakhtiar, R.; Springer, D. L.; Morris, B. J.; Bruce, J. E.; Anderson, G. A.; Edmonds, C. G.; Smith, R. D.: Molecular Weight Determination of Plasmid DNA Using Electrospray Ionization Mass Spectrometry, Nucleic Acids Res. 1996, 24 (11), 2183-2189, doi:10.1093/nar/24.11.2183.

(215) Schultz, J. C.; Hack, C. A.; Benner, W. H.: Mass Determination of Megadalton-DNA Electrospray Ions Using Charge Detection Mass Spectrometry, J. Am. Soc. Mass Spectrom. 1998, 9 (4), 305-

313, doi:10.1016/S1044-0305(97)00290-0.

(216) Fuerstenau, S. D.; Benner, W. H.: Molecular Weight Determination of Megadalton DNA Electrospray Ions Using Charge Detection Time-of-Flight Mass Spectrometry, Rapid Com. Mass Spectrom. 1995, 9 (15), 1528-1538, doi:10.1002/rcm.1290091513.

(217) Konermann, L.; Ahadi, E.; Rodriguez, A. D.; Vahidi, S.: Unraveling the Mechanism of Electrospray Ionization, Anal. Chem.

2012, 85 (1), 2-9, doi:10.1021/ac302789c.

(218) Pang, D.; Thierry, A. R.; Dritschilo, A.: DNA Studies Using Atomic Force Microscopy: Capabilities for Measurement of Short DNA Fragments, Front. Mol. Biosci. 2015, 2, 1-7, doi:10.3389/fmolb.2015.00001.

(219) Rauschenbach, S.: Accurate Ringshape of Circulare DNA May Be Caused by Electrostatic Repulsion, Private Comm. 2020.

(220) Kruve, A.; Rebane, R.; Kipper, K.; Oldekop, M.-L.; Evard, H.; Herodes, K.; Ravio, P.; Leito, I.: Tutorial Review on Validation of Liquid Chromatography-Mass Spectrometry Methods: Part II, Anal. Chim. Acta 2015, 870, 8-28, doi:10.1016/j.aca.2015.02.016.

(221) Wilm, M.; Mann, M.: Analytical Properties of the Nanoelectrospray Ion Source, Anal. Chem. 1996, 68 (1), 1-8, doi:10.1021/ac9509519.

(222) El-Faramawy, A.; Siu, K. W. M.; Thomson, B. A.: Efficiency of Nano-Electrospray Ionization, J. Am. Soc. Mass Spectrom. 2005, 16 (10), 1702-1707, doi:10.1016/j.jasms.2005.06.011.
(223) Volny, M.; Turecek, F.: High Efficiency in Soft Landing of Biomolecular Ions on a Plasma-Treated Metal Surface: Are DoubleDigit Yields Possible ?, J. Mass Spectrom. 2006, 41 (1), 124-126, doi:10.1002/jms.969.

(224) Cox, J. T.; Marginean, I.; Smith, R. D.; Tang, K.: On the Ionization and Ion Transmission Efficiencies of Different ESI-MS Interfaces, J. Am. Soc. Mass. Spectrom. 2014, 26 (1), 55-62, doi:10.1007/s13361-014-0998-5.

(225) Alvarez, J.; Futrell, J. H.; Laskin, J.: Soft-Landing of Peptides onto Self-Assembled Monolayer Surfaces, J. Phys. Chem. A 2006, 110, 1678-1687, doi:10.1021/jp0555044.

(226) Ran, W.; Walz, A.; Stoiber, K.; Knecht, P.; Xu, H.; Papageorgiou, A. C.; Huettig, A.; Cortizo-Lacalle, D.; Mora-Fuentes, J. P.; Mateo-Alonso, A.; Schlichting, H.; Reichert, J.; Barth, J. V.: Depositing Molecular Graphene Nanoribbons on $\operatorname{Ag}(111)$ by Electrospray Controlled Ion Beam Deposition: Self-Assembly and On-Surface Transformations, Submitted Angewandte Chemie 2021. 